\title{
Cloud condensation nuclei activity and droplet activation kinetics of wet processed regional dust samples and minerals
}

\author{
P. Kumar ${ }^{1, *}$, I. N. Sokolik ${ }^{2}$, and A. Nenes ${ }^{1,2}$ \\ ${ }^{1}$ School of Chemical \& Biomolecular Engineering, Georgia Institute of Technology, Atlanta, GA, 30332, USA \\ ${ }^{2}$ School of Earth \& Atmospheric Sciences, Georgia Institute of Technology Atlanta, GA, 30332, USA \\ *now at: SABIC-Innovative Plastics, 1 Noryl Avenue, Selkirk, NY, 12158, USA
}

Received: 1 April 2011 - Published in Atmos. Chem. Phys. Discuss.: 21 April 2011

Revised: 27 July 2011 - Accepted: 2 August 2011 - Published: 25 August 2011

\begin{abstract}
This study reports laboratory measurements of particle size distributions, cloud condensation nuclei (CCN) activity, and droplet activation kinetics of wet generated aerosols from clays, calcite, quartz, and desert soil samples from Northern Africa, East Asia/China, and Northern America. The dependence of critical supersaturation, $s_{\mathrm{c}}$, on particle dry diameter, $D_{\text {dry }}$, is used to characterize particle-water interactions and assess the ability of Frenkel-Halsey-Hill adsorption activation theory (FHH-AT) and Köhler theory (KT) to describe the CCN activity of the considered samples. Wet generated regional dust samples produce unimodal size distributions with particle sizes as small as $40 \mathrm{~nm}, \mathrm{CCN}$ activation consistent with KT, and exhibit hygroscopicity similar to inorganic salts. Wet generated clays and minerals produce a bimodal size distribution; the CCN activity of the smaller mode is consistent with KT, while the larger mode is less hydrophilic, follows activation by FHH-AT, and displays almost identical CCN activity to dry generated dust. Ion Chromatography (IC) analysis performed on regional dust samples indicates a soluble fraction that cannot explain the $\mathrm{CCN}$ activity of dry or wet generated dust. A mass balance and hygroscopicity closure suggests that the small amount of ions (from low solubility compounds like calcite) present in the dry dust dissolve in the aqueous suspension during the wet generation process and give rise to the observed small hygroscopic mode. Overall these results identify an artifact that may question the atmospheric relevance of dust $\mathrm{CCN}$ activity studies using the wet generation method.
\end{abstract}

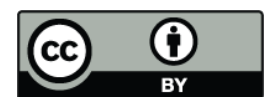

Correspondence to: A. Nenes (athanasios.nenes@gatech.edu)
Based on the method of threshold droplet growth analysis, wet generated mineral aerosols display similar activation kinetics compared to ammonium sulfate calibration aerosol. Finally, a unified CCN activity framework that accounts for concurrent effects of solute and adsorption is developed to describe the CCN activity of aged or hygroscopic dusts.

\section{Introduction}

The ability of aerosols to act as cloud condensation nuclei $(\mathrm{CCN})$ can be characterized based on their size, chemical composition, and the level of water vapor supersaturation in ambient clouds. Mineral aerosol (or dust) has been recognized as an important atmospheric constituent because of its ability to act as CCN, giant CCN (GCCN) (e.g., Rosenfeld et al., 2001; Levin and Cotton, 2008), or ice nuclei (IN) (e.g., DeMott et al., 2003; Field et al., 2006). Despite its well recognized importance, mineral aerosol poses a challenge in atmospheric models due to its compositional complexity, nonsphericity and atmospheric lifetime leading to poorly quantified dust-cloud interactions.

Mineral aerosol originates mainly from arid and semiarid desert regions of the world (e.g., Sahara, Taklamakan, and Gobi) and consists of clays (e.g., kaolinite, illite, and montmorillonite), carbonates (e.g., calcite, dolomite), iron oxides (e.g., hematite, goethite) and quartz (Lafon et al., 2006). Dust particles are often transported over long distances downwind from their source regions. During their transport, dust particles undergo atmospheric processing to form soluble species (like sulfates) on the dust surface (e.g., Levin et al., 1996) that have important impacts on dust CCN activity (Kelly et al., 2007). 
Two classes of theory have been proposed to describe the CCN activity of mineral aerosol: Köhler theory (KT) (Köhler, 1936), where hygroscopicity is driven by the amount of solute in the dust, and, by more recent FHH (Frenkel, Halsey, and Hill) adsorption activation theory (AT) (Sorjamaa and Laaksonen, 2007; Kumar et al., 2009a, b) that explicitly considers the effect of water vapor adsorption on the dust surface. Almost all published experimental studies on CCN activity of fresh dust (e.g., Koehler et al., 2009; Herich et al., 2009) parameterize laboratory observations using the KT framework on the assumption that dust $\mathrm{CCN}$ activity is controlled solely by the amount of soluble salts in the mineral aerosol, with the insoluble fraction not affecting water activity. However, studies that measured soluble ions composition on dust samples collected from various dust source regions (e.g., Song et al., 2005; Radhi et al., 2010) indicated negligible amounts of soluble salts. In a recent study, Kumar et al. (2011) compared the power law exponent derived from the experimental $s_{\mathrm{c}}-D_{\text {dry }}$ relationship with those determined from FHH-AT and KT, and suggested that FHHAT is a better representation than KT for CCN activity of dry generated dust devoid of a soluble fraction. However, Kumar et al. (2009a) found that KT applies for dusts with a considerable salt fraction such as those generated from dry lakebed mixed with salts (e.g., Owens Lake; Koehler et al., 2009) or mineral dust exposed to considerable cloud processing or aging (Levin et al., 1996). Based on this, Kumar et al. (2009a) suggested combining KT and FHH-AT to comprehensively describe $\mathrm{CCN}$ activity of mineral aerosol (with droplet nucleation occurring via both adsorption and solute effects) throughout its atmospheric lifetime. To account for adsorption activation CCN in atmospheric models, Kumar et al. (2009b) developed a cloud droplet formation parameterization where the $\mathrm{CCN}$ constitutes an external mixture of soluble aerosol (that follow KT) and insoluble aerosol (that follow FHH-AT).

Recent laboratory measurements of $\mathrm{CCN}$ activity of dust and calcium minerals (Hatch et al., 2008; Koehler et al., 2009; Herich et al., 2009; Sullivan et al., 2009), subsaturated hygroscopicity measurements (Gustafsson et al., 2005; Vlasenko et al., 2005; Herich et al., 2009), size distributions and chemical reactivity (Hudson et al., 2008; Gibson et al., 2006), and ice cloud particle nucleation (e.g., Koehler et al., 2009) have utilized the well-established technique of generating aerosol via atomization from an aqueous dust suspension. Recently, Sullivan et al. (2010) showed that wet atomization of calcium minerals with considerably low solubility in water (typical of mineral aerosol composition) can induce artifacts in the dust properties to the point where they may not represent dust aerosols in the atmosphere. This has not been explored for atmospheric dusts and minerals or clays.

In this study, $\mathrm{CCN}$ activity and droplet activation kinetics measurements of regional dust and mineral aerosol generated by wet atomization technique are performed to quantify biases introduced in the observed $\mathrm{CCN}$ activity and physical properties of dusts, and selected minerals and clays. Contribution of the soluble salts present in fresh dust samples to dust CCN activity is also investigated. The results obtained here are then compared against properties of fresh dust dry generated by a soft-saltation technique (Kumar et al., 2011). The effect of wetting dust and mineral samples in aqueous solution to generate aerosol and its implication to particles number size distributions, $\mathrm{CCN}$ activation, and droplet activation kinetics is provided in Sects. 4.1, 4.2, and 4.3, respectively. The contribution of soluble salts to dust CCN activity is also evaluated in Sect. 4.4. Finally, Sect. 5 discusses implications for dust-warm cloud interactions and presents a new $\mathrm{CCN}$ activity framework that combines both solute and water vapor adsorption effects for dust-cloud interactions. The conclusions and summary of this work is presented in Sect. 6.

\section{Experimental methods}

\subsection{Regional dust samples and individual minerals}

Aerosols from regional soil samples and individual minerals/clays were generated and characterized in this study. Niger soil collected from the Sahel source region $\left(13^{\circ} 31^{\prime} \mathrm{N}\right.$, $2^{\circ} 38^{\prime} \mathrm{E}$ ) was used as representative of African dust. Asian soil samples were collected from five different East Asia (China) desert locations (Soil 1, eastern edge of the Hexi corridor; Soil 2, south-eastern edge of the Tengger Desert; Soil 3, central Tengger Desert; Soil 4, south-eastern edge of the Taklamakan Desert; Soil 5, southern edge of the Hunshandake Desert). Commercially available Arizona Test Dust was also used in measurements. Analyzed individual minerals included several clays (kaolinite, illite, and montmorillonite) and calcite. These minerals were aerosolized as purchased, with no subsequent treatment prior to atomization.

\subsection{Measurements of $\mathrm{CCN}$ activity and droplet activation kinetics}

The laboratory setup employed to characterize the $\mathrm{CCN}$ activity and droplet activation kinetics of the regional dust samples is described in detail by Kumar et al. (2011) and Padró et al. (2010) and briefly summarized here. Aerosol is generated by atomization of a dust-water suspension containing $2.0 \pm 0.4$ gram of regional dust (mineral/clay) in $100 \mathrm{ml}$ of high purity DI (18 q-grade) water. The atomized droplets are then dried by passing through two silica gel diffusion dryers that maintain a relative humidity less than $5 \%$. The resulting polydisperse dry aerosol is then passed through a $1 \mu \mathrm{m}$ impactor and a series of $\mathrm{Kr}-85$ bipolar chargers to achieve an equilibrium charge distribution. The aerosol is then sent to a Differential Mobility Analyzer (DMA, TSI Model 3081) that classifies and size-selects the aerosol based on their electrical mobility. The aerosol sample flow rate of $11 \mathrm{~min}^{-1}$ is used with a sheath flow rate of $51 \mathrm{~min}^{-1}$ to select particle sizes up to $500 \mathrm{~nm}$ in electrical mobility diameter. The classified 
aerosol is then mixed with filtered air before being split into two streams. One stream is sent to a Condensation Particle Counter (CPC, TSI Model 2010) that measures Condensation Nuclei $(\mathrm{CN})$ concentration. The second stream is sent to a Droplet Measurement Technology (DMT) Continuous Flow Streamwise Thermal Gradient Chamber (CFSTGC; Roberts and Nenes, 2005; Lance et al., 2006) to measure the fraction of aerosol that act as a $\mathrm{CCN}$ for supersaturations ranging between $0.2 \%$ and $1.0 \%$. The $\mathrm{CCN}$ instrument supersaturation was calibrated with $\left(\mathrm{NH}_{4}\right)_{2} \mathrm{SO}_{4}$ aerosol using the procedure described by Kumar et al. (2011).

$\mathrm{CCN}$ activation curves, aerosol size distribution and droplet size distributions are obtained using Scanning Mobility CCN Analysis (SMCA) (Moore et al., 2010). SMCA relies on the principle of continuously scanning DMA voltage over time to determine particle size based on electrical mobility. During SMCA, the supersaturation in the CFSTGC is maintained constant (between $0.2 \%$ and $1.0 \%$ ) with aerosol flow rate set to $0.51 \mathrm{~min}^{-1}$ and sheath-to-aerosol ratio of 10:1. Aerosol size distributions are measured using a SMPS (Scanning Mobility Particle Sizer) composed of a TSI Model 3081 DMA and a TSI Model 2010 CPC.

$\mathrm{CCN}$ activity is expressed in terms of minimum dry diameter, $D_{\text {dry }}$ of particles that activate into cloud droplets at a critical supersaturation, $s_{\mathrm{c}}$. $D_{\mathrm{dry}}$ is determined by fitting a sigmoid curve to the experimentally determined CCN to $\mathrm{CN}$ concentration ratio with respect to dry particle diameter. Dry critical diameter, $D_{\text {dry }}$ is then the diameter for which $50 \%$ of the particles activate at $s_{\mathrm{c}}$ equal to the instrument supersaturation. The contribution from larger multiple charged particles (in this study, up to +3 ) are accounted for using the approach of Moore et al. (2010).

Droplet activation kinetics for dust $\mathrm{CCN}$ is also inferred using SMCA. This is done by comparing the droplet size, $D_{\mathrm{p}}$, at the optical particle counter (OPC) of CFSTGC for particles generated from regional dusts with that from calibration $\left(\mathrm{NH}_{4}\right)_{2} \mathrm{SO}_{4}$ aerosol with $s_{\mathrm{c}}$ equal to instrument supersaturation. The calibration is used as a standard of activation kinetics. If $D_{\mathrm{p}}$ is lower than the calibration, the dust may be subject to kinetic retardations. This technique is called "Threshold Droplet Activation Kinetics (TDGA)", and has been successfully used in a number of in-situ and laboratory studies (Bougiatioti et al., 2009; Padró et al., 2010, Kumar et al., 2011). As the comparison is made against $\left(\mathrm{NH}_{4}\right)_{2} \mathrm{SO}_{4}$ aerosol that activates according to KT, uncertainty is introduced in the determination of activation kinetics by TDGA, (owing to the difference in critical wet diameter between KT and FHH-AT particles). However, a computational fluid dynamics model of the CCN instrument (Kumar et al., 2011) can be used to comprehensively simulate the growth of $\mathrm{CCN}$ and appropriately account for size shifts from differences in KT and FHH-AT. Any residual droplet size difference can be attributed to delayed activation kinetics and parameterized as changes in the water vapor uptake coefficient, $\alpha_{\mathrm{c}}$.

\subsection{Soluble ions measurements}

\subsubsection{Particle sample collection}

A 12 stage Micro Orifice Uniform Deposition Impactor (MOUDI, Model 110, MSP Corp.) was used to collect dry generated and size-resolved particles to determine their soluble fraction. The stage cuts of MOUDI are 18.0, 10.0, 5.6, $3.2,1.8,1.0,0.56,0.32,0.18,0.1$, and $0.056 \mu \mathrm{m}$ aerodynamic diameter, plus an after filter $(<0.056 \mu \mathrm{m})$. The flowrate of the MOUDI is set to $301 \mathrm{~min}^{-1}$. The collection substrates used in the first 11 stages include $47 \mathrm{~mm}$ Aluminium foil disks. A thin layer of Heavy-Duty Silicone Spray (MSP corp.) is applied to the foil substrates to minimize particle bounce. The substrates were weighed before and after the sampling using weighing scale (OHAUS Corp., AR0640) to determine the mass of dust deposited at each impactor stage. To ensure sufficient mass for composition measurements, sample collection is done for several hours, and grouping of substrates was performed. Stages corresponding to aerodynamic diameters greater than $1.0 \mu \mathrm{m}$ were grouped and will be referred to as coarse mode. Aerosol particles collected at stages with aerodynamic diameters equal to and less than $1.0 \mu \mathrm{m}$ will be referred to as fine mode.

The dry aerosol collected in the MOUDI was generated following Kumar et al. (2011). Approximately 10-15 grams of the desired sample was introduced in the $1000 \mathrm{ml}$ sealed Erlenmeyer flask attached to a Burrell-Wrist Action Shaker (Model 75). Compressed filtered air is introduced into the flask that generates polydisperse fine aerosols by mechanical disintegration (saltation) with a distribution that resembles the natural size distributions of dust particles generated in source regions (Lafon et al., 2006).

\subsubsection{Ion chromatography analysis}

After particle collection, the substrates were placed in a Nalgene HDPE bottle with 20-24 ml of 18 q-grade deionized (DI) water for extraction. Each bottle was sonicated and heated in a water bath (at $\sim 60^{\circ} \mathrm{C}$, Padró et al., 2010) for $75 \mathrm{~min}$. The solution was then allowed to cool for $3 \mathrm{~h}$ and filtered through a $0.45 \mu \mathrm{m}$ pore syringe filter to remove the insoluble particles suspended in solution.

The concentration of major ions in the filtered extract solution was measured with Ion Chromatography (IC, Dionex Model DX500). The IC used in this study has two channels allowing concurrent measurements of anions and cations. Anions were measured using an AS11 column, an ASRS ultra-suppressor, and a gradient elute of sodium hydroxide. Cations were determined using a CS12 column and CSRS ultra-suppressor and methanesulfonate acid eluent. Anions measured included acetate $\left(\mathrm{C}_{2} \mathrm{H}_{3} \mathrm{O}_{2}^{-}\right)$, chloride $\left(\mathrm{Cl}^{-}\right)$, formate $\left(\mathrm{HCOO}^{-}\right)$, nitrate $\left(\mathrm{NO}_{3}^{-}\right)$, nitrite $\left(\mathrm{NO}_{2}^{-}\right)$, oxalate $\left(\mathrm{C}_{2} \mathrm{O}_{4}^{2-}\right)$ and sulfate $\left(\mathrm{SO}_{4}^{2-}\right)$. The cations measured were ammonium $\left(\mathrm{NH}_{4}^{+}\right)$, calcium $\left(\mathrm{Ca}^{2+}\right)$, potassium 
$\left(\mathrm{K}^{+}\right)$and sodium $\left(\mathrm{Na}^{+}\right)$. The ion concentrations obtained from IC measurements were then used as input for the ISORROPIA-II thermodynamic equilibrium model (Fountoukis and Nenes, 2007) to predict the mixture of inorganic salts present in the samples.

\section{Experimental analysis}

To describe the CCN activity of dust particles, two phenomena must be accounted for: (i) the effect of adsorption of water vapor on the insoluble dust particles represented by the FHH adsorption activation theory (FHH-AT) (Kumar et al., 2009a, b), and, (ii) the effect of solute (which may be present in freshly emitted dust or formed during atmospheric aging) represented by the Raoult effect in Köhler Theory (KT) (Köhler, 1936).

\subsection{FHH Adsorption Activation Theory (FHH-AT)}

The AT used here is developed with the multilayer FHH adsorption isotherm model (Sorjamaa and Laaksonen, 2007; Kumar et al., 2009a,b) and contains two adjustable parameters $\left(A_{\mathrm{FHH}}\right.$ and $\left.B_{\mathrm{FHH}}\right)$ that describe the contribution of water vapor adsorption on $\mathrm{CCN}$ activity. $A_{\mathrm{FHH}}, B_{\mathrm{FHH}}$ are determined by least squares fitting of the observed $s_{\mathrm{c}}, D_{\text {dry }}$ to the maxima of the FHH-AT water vapor equilibrium curves (Sorjamaa and Laaksonen, 2007; Kumar et al., 2009b):

$s=\frac{4 \sigma_{\mathrm{w}} M_{\mathrm{w}}}{R T \rho_{\mathrm{w}} D_{\mathrm{p}}}-A_{\mathrm{FHH}}\left(\frac{D_{\mathrm{p}}-D_{\mathrm{dry}}}{2 D_{\mathrm{H}_{2} \mathrm{O}}}\right)^{-B_{\mathrm{FHH}}}$

where $s$ is the supersaturation, $D_{\text {dry }}$ is the dry CCN diameter, $D_{\mathrm{H}_{2} \mathrm{O}}$ is the diameter of water molecule (equal to $2.75 \AA$, Kumar et al., 2009b), $D_{\mathrm{p}}$ is the droplet diameter, $\sigma_{\mathrm{w}}$ is the $\mathrm{CCN}$ surface tension at the point of activation (Pruppacher and Klett, 1997), $\rho_{\mathrm{w}}$ is the water density, $M_{\mathrm{w}}$ is the molar mass of water, $R$ is the universal gas constant, and $T$ is the average column temperature. The value of $B_{\mathrm{FHH}}$ is a measure of the particle hydrophilicity with lower $B_{\mathrm{FHH}}$ values corresponding to a more hydrophilic particle. As $B_{\mathrm{FHH}}$ increases, particles become less hydrophilic and resemble insoluble (but wettable) particles that follow the Kelvin equation (Kumar et al., 2011). Kumar et al. (2011) found that the $\mathrm{CCN}$ activity of dry generated aerosols from regional dust samples considered in this work, are well described by FHHAT with $A_{\mathrm{FHH}}=2.25 \pm 0.75$ and $B_{\mathrm{FHH}}=1.20 \pm 0.10$.

\section{$3.2 \kappa$-Köhler Theory $(\kappa-\mathrm{KT})$}

The CCN activity of an aerosol particle with appreciable amounts of solute can be described using Köhler theory (KT). In this study, solute effects are parameterized using the hygroscopicity parameter, $\kappa$, approach (Petters and Kreidenweis, 2007) that collectively accounts for the density, molar mass, and dissociation effects of solute on water activity (the Raoult term in the Köhler equation). The $\kappa$ can be used to directly compare the hygroscopicity of aerosol over a wide range of composition, with $\kappa \rightarrow 0$ for completely insoluble material to $\kappa \rightarrow 1.4$ for $\mathrm{NaCl}$ (the most hygroscopic of atmospheric aerosol species).

When $\kappa>0.2, \kappa$ can be obtained from $s_{\mathrm{c}}-D_{\text {dry }}$ pairs given by the following approximate expression:

$\kappa=\frac{4 A^{3}}{27 D_{\mathrm{dry}}^{3} s_{\mathrm{c}}^{2}}$

where $A=\frac{4 \sigma_{\mathrm{w}} M_{\mathrm{w}}}{\rho_{\mathrm{w}} R T}, s_{\mathrm{c}}$ is the instrument supersaturation, and $D_{\text {dry }}$ is the minimum dry particle activation diameter at $s_{\mathrm{c}}$. Lower values of $\kappa$ (e.g., $\kappa<0.05)$ that are more relevant to the dust $s_{\mathrm{c}}-D_{\text {dry }}$ experimental relationships are calculated from the numerical solution of:

$s=\frac{4 \sigma_{\mathrm{w}} M_{\mathrm{w}}}{R T \rho_{\mathrm{w}} D_{\mathrm{p}}}-\frac{D_{\mathrm{dry}}^{3} \kappa}{D_{\mathrm{p}}^{3}-D_{\mathrm{dry}}^{3}(1-\kappa)}$

All studies on dust CCN activation, with the exception of Kumar et al. (2011), have parameterized dust CCN activity using the $\kappa$-KT approach, implicitly assuming that $\mathrm{CCN}$ activity of dust is governed by its small soluble fraction.

\section{Results and discussion}

\subsection{Size distributions}

Figure 1a compares the particle number size distribution of aerosols generated from the Niger dust sample (brown squares) and Soil 2 (blue circles). Size distributions were generated using either the dry soft-saltation method (open symbols) described in Kumar et al. (2011) or the wet atomization method (solid symbols). While both generation methods produce particles with a unimodal size distribution (Fig. 1a), the sizes of particles are significantly different. For instance, wet generated Niger dust (brown curve) has a mean diameter of $\sim 40 \mathrm{~nm}$ while dry generated dust peaks at $\sim 450 \mathrm{~nm}$. Similar differences are observed for Soil 2 (blue curve) where median diameters are $41 \mathrm{~nm}$ and 400 for wet and dry generated dust, respectively. This demonstrates that particles generated via wet atomization technique can be up to ten times smaller than those generated by the dry saltation technique.

In the case of ATD, the wet atomization method generated a bimodal dry size distribution (Fig. 1b) with a dominant first peak centered at a modal diameter of $\sim 35 \mathrm{~nm}$, and a second peak with reduced number concentration centered at a modal diameter $\sim 240 \mathrm{~nm}$. For comparison, the number size distribution for ATD generated by the dry technique (Fig. 1b) produces a peak centered at $\sim 340 \mathrm{~nm}$. This suggests that the second observed peak in the wet generation method could be primarily dust particles internally mixed with material from the first hygroscopic peak. Similar behavior was also observed for kaolinite particles (Fig. 1b). 

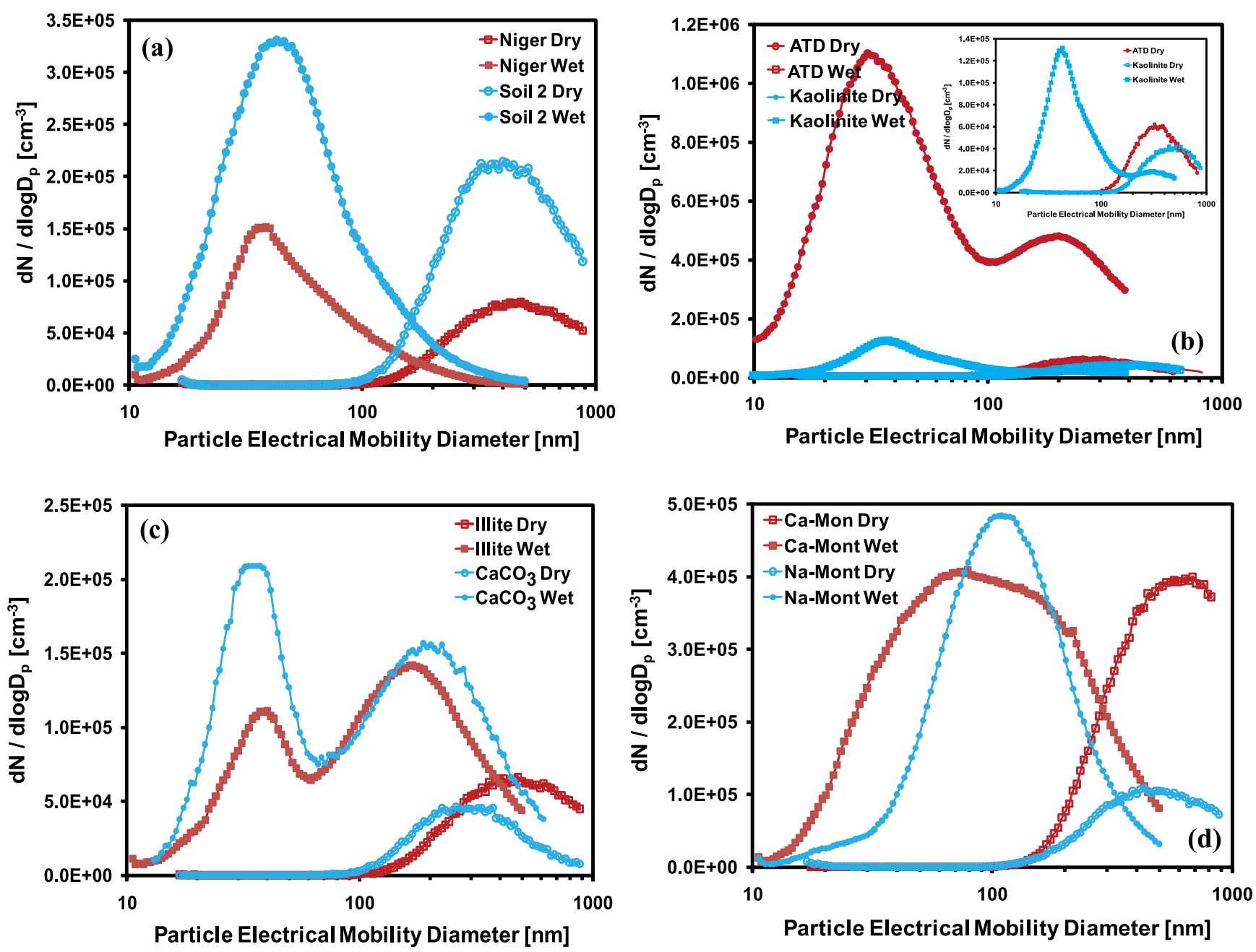

Fig. 1. Particle number size distribution measured by the SMPS system via dry generated and wet generated techniques for (a) Niger Soil and East Asian Soil 2, (b) ATD and Kaolinite, (c) Illite and $\mathrm{CaCO}_{3}$ and (d) Montmorillonite (Na-rich and Ca-rich).

Dry and wet generated size distributions are provided as inset in Fig. 1b; bimodal distribution with peaks at $\sim 34 \mathrm{~nm}$ and $\sim 300 \mathrm{~nm}$ are seen. For dry generated kaolinite aerosol, however, a unimodal distribution is observed with a peak centered at $\sim 500 \mathrm{~nm}$. A similar behavior in terms of the bimodal distribution (with the dominant peak at smaller sizes and minor peak at larger sizes) was observed by Sullivan et al. (2010) for the Solvay calcite system.

Like in the case of ATD and kaolinite, a bimodal size distribution is observed for wet generated illite and $\mathrm{CaCO}_{3}$ particles (Fig. 1c). However, the relative strength of both modes is reversed, with the peak at $\sim 37 \mathrm{~nm}$ diameter being less prominent than that observed at $\sim 160 \mathrm{~nm}$. Similarly for wet generated $\mathrm{CaCO}_{3}$ aerosol (solid blue circle), the minor and major peaks were centered at $\sim 33 \mathrm{~nm}$ and $\sim 200 \mathrm{~nm}$, respectively. Dry generated illite (open brown) and $\mathrm{CaCO}_{3}$ (open blue) aerosols exhibit a unimodal size distribution with a mean diameter $\sim 460 \mathrm{~nm}$ and $\sim 250 \mathrm{~nm}$, respectively.
Most commonly found clay minerals in regional dust samples are kaolinite, illite, and montmorillonite (Usher et al., 2003). Depending on the aluminosilicate layer-layer interactions (charge-countering cations, van der Waals forces, or hydrogen bonds), clays can be classified as swelling or nonswelling (Farmer, 1974). Illite and kaolinite are non-swelling clays because of strong inter-ionic and hydrogen bond interactions that prevent expansion in the presence of water. In contrast, montmorillonite can contain unbounded $\mathrm{Na}^{+}$ and $\mathrm{Ca}^{+}$ions that can hydrate in the presence of water and make clays swell. The differences in interactions of water with the internal clay structure may lead to large changes in the particle size distributions for montmorillonite clay (Narich and Ca-rich) generated via the wet atomization and dry soft-saltation techniques (Fig. 1d). It can be also inferred that swelling (montmorillonite) and non-swelling (illite and kaolinite) clays produce the systems with different particlewater interactions in aqueous solutions. This difference in water interaction is also consistent with previous studies on 


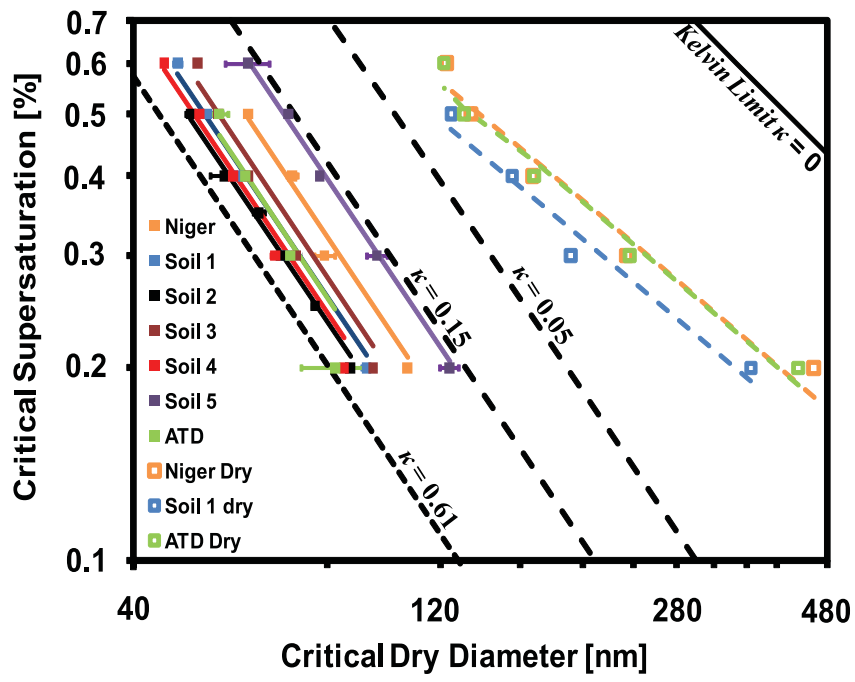

Fig. 2. CCN activation curves for different dust types considered in this study. Solid symbols refer to wet generated CCN activity and solid lines show $\kappa$-KT fits. Open symbols refer to dry generated $\mathrm{CCN}$ activity and dashed line are FHH adsorption activation fits (Data obtained from Kumar et al., 2011). Also shown in black dashed lines are $\kappa$-KT lines.

hygroscopicity measurements where water uptake ability of montmorillonite was found to be similar to that of zeolite that contains internal pores for water adsorption (Schuttlefield et al., 2007). Observed differences in water interactions also manifest as differences in $\mathrm{CCN}$ activity between swelling and non-swelling clays (shown in Sect. 4.2.2).

\subsection{CCN activation results}

\subsubsection{Regional dust samples}

The CCN activity ( $s_{\mathrm{c}}$ versus $D_{\text {dry }}$ ) measured for wet generated dust aerosol is presented in Fig. 2. The KT fits to the experimental data are shown with solid lines. For comparison, the CCN activation curves for dry generated dust (open symbols) are also shown with their corresponding FHH-AT fits. It is evident that the wet generated particles were significantly more $\mathrm{CCN}$ active than those generated from the dry soft-saltation technique. For all wet samples, $\kappa$ ranges between $0.15-0.61$, which is considerably higher than the equivalent $\kappa(=0.05)$ for dry generated dust (Kumar et al., 2011). Increased hygroscopicity after wetting is consistent with previous studies on dust-CCN activity that used similar wet generation techniques (e.g., Koehler et al., 2009; Herich et al., 2009).

It can be seen that within experimental uncertainty, $x_{\exp }$ for all wet-generated dust types (with the exception of ATD) is about -1.5 . This suggests that KT provides a good framework for representing CCN activity in this case. The hygroscopicity parameter, $\kappa$, for wet-generated Niger, Asian and ATD samples were found to be slightly below that of
Table 1. CCN activation results - experimental exponents, and hygroscopicity parameter $(\kappa)$ for regional dust samples generated from wet atomization method. Results from dry-generation experiments are also shown for comparison.

\begin{tabular}{lccc}
\hline Soil & $x_{\exp }($ wet $)$ & $\kappa$ & $x_{\exp }^{\mathrm{a}}($ dry $)$ \\
\hline Niger & -1.63 & 0.26 & $-0.79 \pm 0.02+(0.04)$ \\
Soil 1 & -1.63 & 0.39 & $-0.84 \pm 0.02+(0.05)$ \\
Soil 2 & -1.56 & 0.48 & $-0.82 \pm 0.02+(0.05)$ \\
Soil 3 & -1.71 & 0.34 & $-0.92 \pm 0.03+(0.05)$ \\
Soil 4 & -1.73 & 0.44 & $-0.88 \pm 0.03+(0.04)$ \\
Soil 5 & -1.53 & 0.17 & $-0.78 \pm 0.03+(0.05)$ \\
ATD $^{\mathrm{b}}$ & -2.16 & 0.40 & $-0.82 \pm 0.02+(0.04)$ \\
\hline
\end{tabular}

a represents experimental exponent determined from dry generation method Kumar et al. (2011). Values in parentheses indicate change in magnitude of $x_{\exp }$ from change in dynamic shape factor between 1.1 and 1.5 .

b Two peaks were observed for ATD. Wet atomization values here represent experimental results from the first (most hygroscopic) peak.

$\left(\mathrm{NH}_{4}\right)_{2} \mathrm{SO}_{4}(\kappa=0.61)$. In the case of ATD, a bimodal size distribution was obtained (Fig. 1b). While performing CCN activation measurements on wet generated ATD aerosol, almost all particles of the second peak activated (with an activation fraction $\sim 1.0$ ). Therefore, in this analysis we fit a sigmoid curve to the experimental points of activation fraction generated from the dominant first mode. Results indicated that the CCN activity of wet generated ATD can be parameterized with $\kappa=0.40$ (compared to $\kappa<0.05$ for dry generated ATD). As $x_{\exp }$ is expected to range between -0.8 (corresponding to $\mathrm{FHH}-\mathrm{AT}$ ) and -1.5 (corresponding to $\mathrm{KT}$ ), the unusual $x_{\exp }$ (equal to -2.15) for ATD can be a consequence of sparingly soluble species such as $\mathrm{CaSO}_{4}$ (Padró and Nenes, 2007), a strong size-dependant composition or activation physics (AT vs. KT).

Kumar et al. (2009a, 2011) showed that the value of $x_{\exp }$ can be used to infer the mechanism that dominates particlewater interaction (i.e., adsorption or solute). $x_{\exp } \sim-1.5$ indicates that the solute effect dominates (hence KT applies), while $x_{\exp }$ between -0.8 and -1.2 indicates the dominance of the water vapor adsorption effect (hence FHH-AT applies). When this is applied to the wet generated data, it is seen from Table 1 that $x_{\exp }$ differs significantly from those determined by dry generation (Kumar et al., 2011). For almost all wet generated regional dust aerosols, $x_{\exp }$ is $\sim-1.5$ (with the exception of ATD; Table 1), while a much lower $x_{\exp } \sim-(0.9 \pm 0.2)$ was observed for dry generated dust aerosol. Thus FHH-AT describes fresh dry dust-CCN activation, while KT describes wet generated dust $\mathrm{CCN}$ activity. An $x_{\exp } \sim-1.5$ and $\kappa \sim 0.4$ correspond to an aerosol mostly composed of soluble salt. The IC analysis, however, shows negligible amounts of soluble salts present in the dust (Sect. 4.4). This, together with the very small size of the particles generated confirms that the process of wet generation for mineral aerosol leads to particles that do not resemble the 

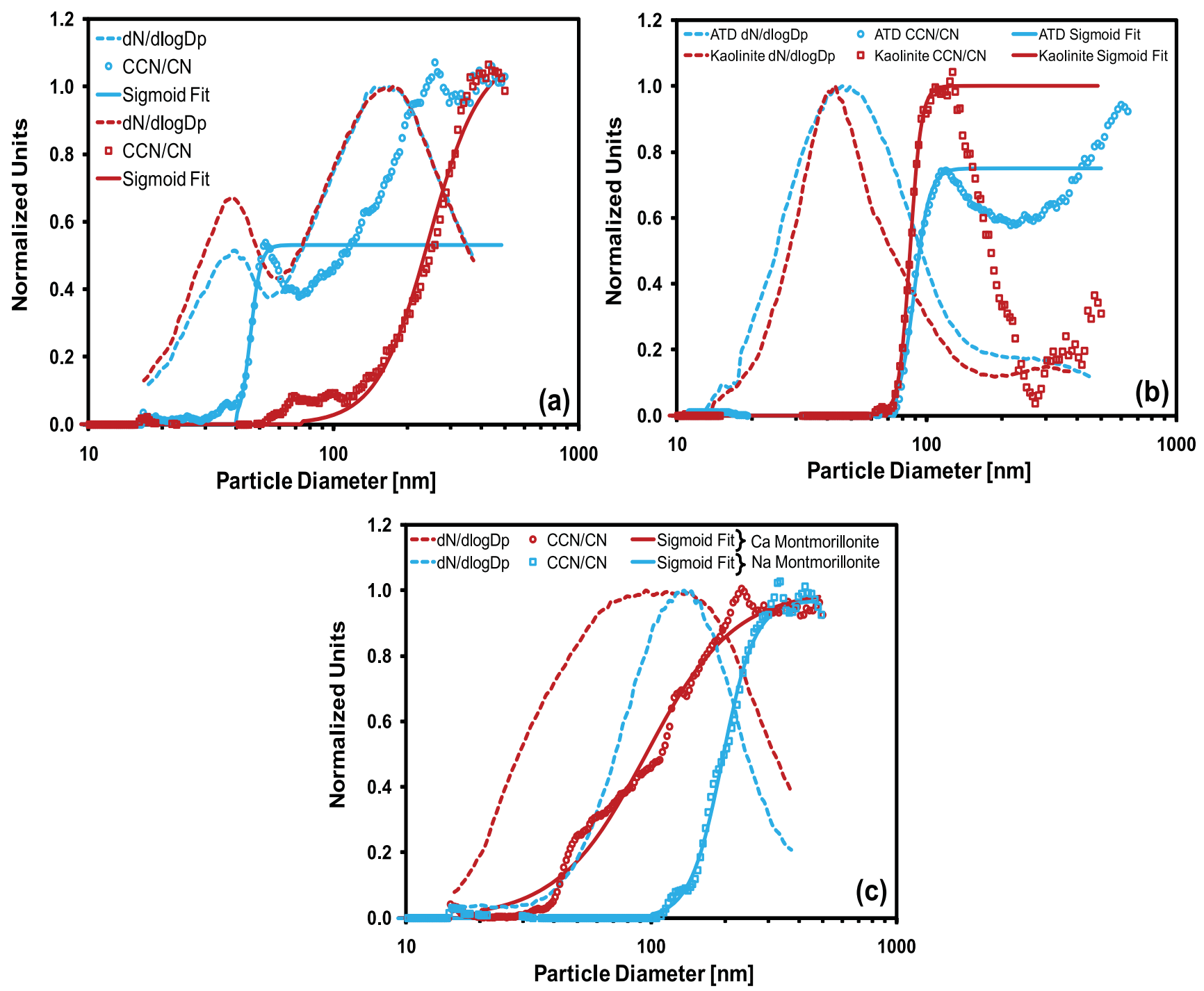

Fig. 3. CCN activation curves for wet generated (a) Illite at supersaturation equal to $0.5 \%$ (open blue square) and supersaturation equal to $0.3 \%$ (open brown square), (b) ATD (open blue square) and Kaolinite (open brown circle) at supersaturation equal to $0.2 \%$, and (c) NaMontmorillonite and Ca-Montmorillonite at supersaturation equal to $0.3 \%$ (open blue square) and supersaturation equal to $0.55 \%$ (open brown circle). Also shown in dashed lines are normalized particle number size distributions for wet generated sample. The sigmoid curve (thick line) is fit to CCN activation data points.

dust suspended in the atomizer (likely composed of soluble salts leached off the original dust), hence the measured physical and chemical properties are likely subject to significant artifacts. A possible explanation for differences in activation mechanisms between dry and wet generated dust is provided in Sect. 4.4.

\subsubsection{Individual minerals and ATD samples}

The CCN activation curves for wet generated illite, ATD, kaolinite and montmorillonite aerosols are shown in Fig. 3. Two sets of CCN activation data were obtained for illite and calcite, reflecting the size-dependent change in composition confirmed by the presence of bimodal size distribution
(Fig. 1c) and double activation curve (Fig. 3a). A similar behavior was observed for kaolinite and ATD (activation curves shown in Fig. 3b). However for kaolinite and ATD, the CCN data $\left(s_{\mathrm{c}}-D_{\text {dry }}\right.$ relationships) could only be determined from the dominant first peak. This is because for kaolinite, too few particles were generated in the minor second peak, while for ATD, almost all particles of the second peak activated even at the lowest supersaturation. For swelling montmorillonite clays (both Na-rich and Ca-rich), only one set of activation data points was obtained as a unimodal size distribution (Fig. 1d) that produced broad activation curves (Fig. 3c). This is consistent with the broad size distributions obtained for wet generated montmorillonite aerosol (Fig. 1d). 
Table 2. $\mathrm{CCN}$ activation results - experimental exponent, hygroscopicity parameter $(\kappa)$, adsorption parameters $\left(A_{\mathrm{FHH}}, B_{\mathrm{FHH}}\right)$ for clays and calcite sample generated from wet atomization method.

\begin{tabular}{lccccc}
\hline Mineral & $x_{\exp }$ & $\kappa$ & $A_{\mathrm{FHH}}$ & $B_{\mathrm{FHH}}$ & $x_{\exp }^{*}$ \\
\hline Illite (Peak 1) & -1.63 & 0.58 & & & $-0.92 \pm 0.03+(0.05)$ \\
Illite (Peak 2) & -0.60 & & 3.00 & 1.27 & $-0.92 \pm 0.03+(0.05)$ \\
Kaolinite & -1.57 & 0.47 & & & \\
$\mathrm{Ca}$ Mont & -0.76 & & 1.09 & 1.04 & $-0.88 \pm 0.02+(0.05)$ \\
$\mathrm{Na} \mathrm{Mont}$ & -0.99 & & 0.87 & 1.00 & $-0.93 \pm 0.02+(0.04)$ \\
$\mathrm{CaCO}_{3}$ (Peak 1) & -1.46 & 1.00 & & & $-0.75 \pm 0.02+(0.05)$ \\
$\mathrm{CaCO}_{3}$ (Peak 2) & -0.89 & & 1.74 & 1.22 & $-0.75 \pm 0.02+(0.05)$ \\
\hline
\end{tabular}

* represents experimental exponent determined from dry generation method Kumar et al. (2011). Values in parentheses indicate change in magnitude of $x$ exp from change in $\chi$ between 1.1 and 1.5 .

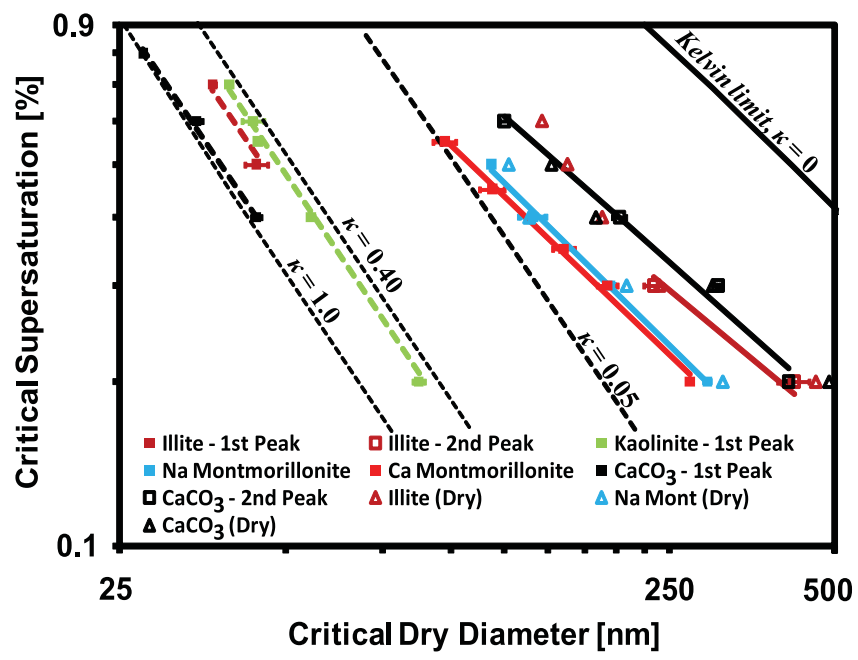

Fig. 4. CCN activation curves for different mineral and clays types considered in this study. Solid and open square $(\boldsymbol{\square}, \square)$ symbols refer to wet generated $\mathrm{CCN}$ activity and dashed lines show $\kappa$-KT fits. Open triangle $(\Delta)$ refers to dry generated $\mathrm{CCN}$ activity and solid lines are FHH adsorption activation fits (obtained from Kumar et al., 2011).

Figure 4 presents the $\mathrm{CCN}$ activity for wet generated calcite and clays considered in this study (solid and open squares). For comparison, the $\mathrm{CCN}$ activity for dry generated minerals (open triangles) is also shown. For samples with evident multi-modal activation, the most hygroscopic mode can readily be parameterized by $\kappa-\mathrm{KT}$, while the second peak is well parameterized by FHH-AT and is in agreement with the $\mathrm{CCN}$ activity of dry generated species. This suggests that the particles generated in the second peak of wet distributions may be closer to the dry generated aerosol as discussed below. The intrinsic hygroscopicity, $\kappa_{\text {int }}$ (Sullivan et al., 2010) of a limited solubility compound such as $\mathrm{CaCO}_{3}$ is equal to 0.97 . This value compares well with $\kappa=1.0$ for the more hygroscopic wet generated $\mathrm{CaCO}_{3}$ peak (Fig. 4) and provides a potential cause for the more hygroscopic KT-like CCN activation data for wet generated regional dusts.
Table 2 shows the values of the experimental exponent, $x_{\text {exp }}$, determined from measurements of the $s_{\mathrm{c}}-D_{\text {dry }}$ relationships for individual minerals and clays generated by wet atomization method. Here $\kappa$ was obtained by fitting $\kappa$-KT to the $\mathrm{CCN}$ activation data corresponding to the more hygroscopic peak and adsorption parameters $\left(A_{\mathrm{FHH}}\right.$ and $\left.B_{\mathrm{FHH}}\right)$ determined from fitting FHH-AT to the less hydrophilic peak. Similar to wet generated regional dust aerosol, clays and calcite yield $\kappa$ approaching values characteristic of soluble inorganic salts (with $\kappa$ for the first peak of $\mathrm{CaCO}_{3}$ being as high as 1.0). The $x_{\exp }$ from the $s_{\mathrm{c}}-D_{\text {dry }}$ relationship from the $\mathrm{CCN}$ activation of the first peak is also $\sim-1.5$ (Table 2). This suggests that particles generated in the more hygroscopic peak follow activation according to KT. The $x_{\exp }$ from the $s_{\mathrm{c}}-D_{\text {dry }}$ data of the less hydrophilic peak is much lower and closer $( \pm 10 \%)$ to $x_{\exp }$ determined from dry generated dust that follow FHH-AT. Furthermore, $B_{\mathrm{FHH}}$ obtained from wet generated dust is $1.20 \pm 0.20$. This value is similar to $B_{\mathrm{FHH}}$ equal to $1.20 \pm 0.10$ for dry generated dust (Kumar et al., 2011). This suggests that water vapor adsorption on dust is reversible, and represents the fate of the dust particle in the atmosphere if it is subjected to multiple evaporation/activation cycles.

\subsection{Droplet activation kinetics}

TDGA is used to study the CCN activation kinetics of wet dust and is based on comparing $D_{\mathrm{p}}$ measured by the OPC at the base of CFSTGC for the sample CCN against that of $\left(\mathrm{NH}_{4}\right)_{2} \mathrm{SO}_{4}$ calibration aerosol. If droplet sizes $\left(D_{\mathrm{p}}\right)$ from dust $\mathrm{CCN}$ are smaller than those from calibration aerosol (with same $s_{\mathrm{c}}$ and for identical conditions of instrument supersaturation), this suggests that mineral aerosol may experience slower growth during their residence time in the instrument. However, if activated droplet sizes are indistinguishable (within experimental uncertainty) from $\left(\mathrm{NH}_{4}\right)_{2} \mathrm{SO}_{4}$ data, wet generated mineral aerosol would exhibit activation kinetics similar to $\left(\mathrm{NH}_{4}\right)_{2} \mathrm{SO}_{4}$ calibration aerosol. 


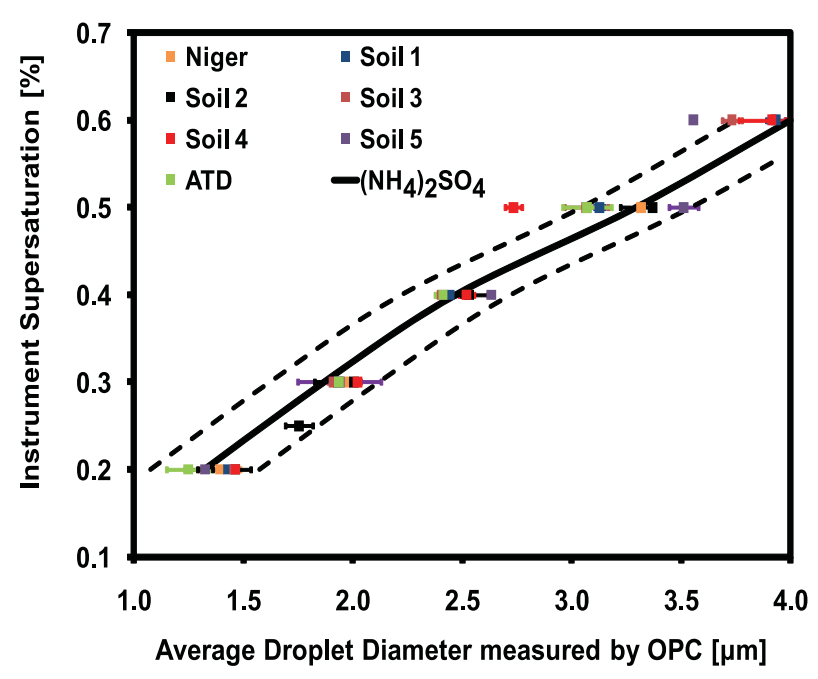

Fig. 5. Activated droplet sizes of wet generated mineral dust $\mathrm{CCN}$ with $s_{\mathrm{c}}$ equal to the instrument supersaturation. Error bars represent variability in droplet sizes as measured by the OPC at same instrument supersaturation. Dashed lines represent $\pm 0.25 \mu \mathrm{m}$ variability in $\left(\mathrm{NH}_{4}\right)_{2} \mathrm{SO}_{4}$ droplet sizes.

Activated droplet sizes obtained for the wet generated regional dusts are shown in Fig. 5. Droplet sizes similar to those generated by $\left(\mathrm{NH}_{4}\right)_{2} \mathrm{SO}_{4}$ aerosol were observed. This suggests that wet generated dust aerosol exhibits activation kinetics similar to $\left(\mathrm{NH}_{4}\right)_{2} \mathrm{SO}_{4}$. In some cases, droplets generated from wet dust aerosol appear to grow $5 \%$ larger compared to pure $\left(\mathrm{NH}_{4}\right)_{2} \mathrm{SO}_{4}$ aerosol. Given the $0.5 \mu \mathrm{m}$ uncertainty (associated with the binning scheme) of the OPC, this larger size is statistically insignificant. A similar behavior was also observed for clays and calcite wet generated (Fig. 6). The $\mathrm{CCN}$ number concentrations in the experiments (either calibration or dust activation) was at most $\sim 1000$ $1500 \mathrm{~cm}^{-3}$ at $D_{\text {dry }}$ so that water vapor depletion effects on $\mathrm{CCN}$ concentration and wet droplet diameter are not important (Lathem and Nenes, 2010) and thus not attributing to increased droplet sizes for dust CCN.

The results presented here suggest that the activation kinetics of wet generated dust are distinctly faster than for dry generated dust (expressed by a 30-80\% reduction in effective water vapor uptake coefficient relative to $\left(\mathrm{NH}_{4}\right)_{2} \mathrm{SO}_{4}$ aerosol). This result suggests that dust particles that already have been wetted in the atomizer have sufficient water coverage to display rapid activation kinetics. It is possible that the wet generated aerosol is not aggressively dried; it may therefore retain a few monolayers of water on its surface and accelerate the rapid re-condensation of water in the CFSTGC (as the water uptake, hence growth kinetics, becomes progressively more rapid with amount of adsorbed water; $\mathrm{Ku}-$ mar et al., 2009a). Rapid activation kinetics is expected for particles primarily composed of soluble salt (which correspond to the high $\kappa$ particles in Figs. 2 and 4).

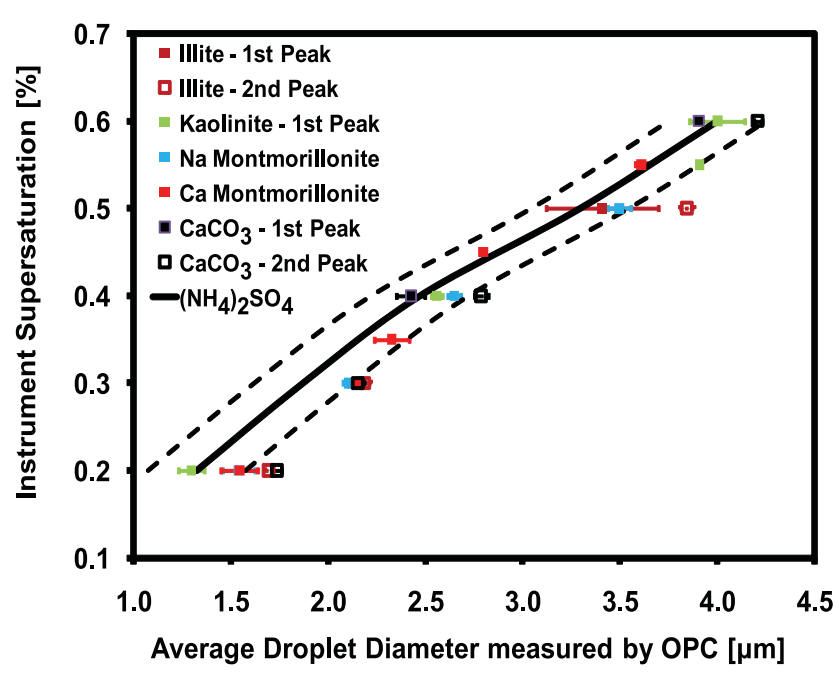

Fig. 6. Activated droplet sizes of wet generated clays and calcite $\mathrm{CCN}$ with $s_{\mathrm{c}}$ equal to the instrument supersaturation. Error bars represent variability in droplet sizes as measured by the OPC at same instrument supersaturation. Dashed lines represent $\pm 0.25 \mu \mathrm{m}$ variability in $\left(\mathrm{NH}_{4}\right)_{2} \mathrm{SO}_{4}$ droplet sizes.

Faster activation kinetics of wet generated dust (compared to dry dust) would imply that the fresh dust in the source regions would behave differently to cloud processed dust downwind of its source region that has undergone multiple activation/evaporation cycles. This would also mean that fresh and cloud processed dust would behave differently even when exposed to the same levels of cloud supersaturation. This is of significance for both Saharan and Asian dusts given that large regions of the world are affected by their mid- and long-range transport. Whether a fresh or cloud processed dust has more significant impact on cloud droplet number would also depend on activation physics and time scales of cloud formation. These issues are further addressed in Sect. 5.

\subsection{Contribution of soluble ions to hygroscopicity}

Previous studies on dust CCN activity (Koehler et al., 2009; Herich et al., 2009) attributed increased hygroscopicity of the wet generated dust aerosol to the presence of soluble salts on dust particles. Kumar et al. (2009a) raised doubts to this based on the slope of the $s_{\mathrm{c}}-D_{\mathrm{dry}}$ relationship. Sullivan et al. (2010) confirmed this for calcite as a negligible mass fraction of soluble salts in calcite aerosol was found using ICP and SEM-EDX. Here we further address this issue by examining the soluble fraction of the regional dust and clay samples and relating it to dust $\mathrm{CCN}$ activation.

The IC analysis was performed on the ATD, Niger, Soil 4, and Soil 5 samples as they represent the globally-important dust source regions. For fine $(\leq 1 \mu \mathrm{m})$ and coarse $(>1 \mu \mathrm{m})$ samples, the ionic concentration obtained from IC (in terms of $\mathrm{mg}^{-1}$ ) is converted to dry ionic mass composition (based 
Table 3. Properties of inorganic salts potentially extracted from regional soil samples. Properties obtained from Padró et al. (2010).

\begin{tabular}{llrrr}
\hline \multicolumn{1}{c}{ Salt } & $\begin{array}{c}\text { Chemical } \\
\text { Formula }\end{array}$ & $\begin{array}{c}\text { Molar Mass } \\
\left(\mathrm{g} \mathrm{mol}^{-1}\right)\end{array}$ & $\begin{array}{r}\rho \\
\left(\mathrm{g} \mathrm{cm}^{-3}\right)\end{array}$ & $\kappa$ \\
\hline Sodium Nitrate & $\mathrm{NaNO}_{3}$ & 84.99 & 2.25 & 0.88 \\
Sodium Sulphate & $\mathrm{Na}_{2} \mathrm{SO}_{4}$ & 142.04 & 2.68 & 0.85 \\
Sodium Bisulphate & $\mathrm{NaHSO}_{4}$ & 120.06 & 2.74 & 0.82 \\
Sodium Chloride & $\mathrm{NaCl}$ & 58.44 & 2.16 & 1.40 \\
Ammonium Chloride & $\mathrm{NH}_{4} \mathrm{Cl}$ & 53.49 & 1.52 & 1.46 \\
Ammonium Nitrate & $\mathrm{NH}_{4} \mathrm{NO}_{3}$ & 80.04 & 1.50 & 0.64 \\
Ammonium Sulphate & $\left(\mathrm{NH}_{4}\right)_{2} \mathrm{SO}_{4}$ & 132.14 & 1.77 & 0.60 \\
Ammonium Bisulphate & $\mathrm{NH}_{4} \mathrm{HSO}_{4}$ & 115.11 & 1.79 & 0.53 \\
Calcium Sulphate & $\mathrm{CaSO}_{4}$ & 136.14 & 2.32 & 0.01 \\
Calcium Nitrate & $\left.\mathrm{Ca}_{4} \mathrm{NO}_{3}\right)_{2}$ & 164.00 & 1.82 & 0.40 \\
Calcium Chloride & $\mathrm{CaCl}_{2}$ & 110.98 & 2.15 & 0.70 \\
Potassium Sulphate & $\mathrm{K}_{2} \mathrm{SO}_{4}$ & 174.27 & 2.66 & 0.69 \\
Potassium Bisulphate & $\mathrm{KHSO}_{4}$ & 136.17 & 2.24 & 0.59 \\
Sodium Carbonate & $\mathrm{Na}_{2} \mathrm{CO}_{3}$ & 105.98 & 2.54 & 1.30 \\
Ammonium Carbonate & $\left(\mathrm{NH}_{4}\right)_{2} \mathrm{CO}_{3}$ & 96.09 & 1.50 & 0.84 \\
Potassium Carbonate & $\mathrm{K}_{2} \mathrm{CO}_{3}$ & 138.20 & 2.29 & 0.90 \\
Calcium Carbonate & $\mathrm{CaCO}_{3}$ & 100.08 & 2.71 & 0.001 \\
\hline
\end{tabular}

Table 4. Soluble volume fraction $\left(\varepsilon_{\mathrm{S}}\right)$, insoluble volume fraction $\left(\varepsilon_{\mathrm{i}}\right)$, and inferred hygroscopicity parameter $(\kappa)$ for mineral dust aerosol samples. Uncertainties in volume fractions are estimated to being less than $0.3 \%$.

\begin{tabular}{lccc}
\hline Sample & $\varepsilon_{\text {soluble }}$ & $\varepsilon_{\text {insoluble }}$ & $\kappa_{\text {mix }}$ \\
\hline ATD - Coarse & 0.007 & 0.993 & 0.003 \\
ATD - Fine & 0.009 & 0.991 & 0.004 \\
Niger - Coarse & 0.004 & 0.996 & 0.001 \\
Niger - Fine & 0.003 & 0.997 & 0.001 \\
Soil 4 - Coarse & 0.014 & 0.986 & 0.003 \\
Soil 4 - Fine & 0.086 & 0.914 & 0.016 \\
Soil 5 - Coarse & 0.003 & 0.997 & 0.001 \\
Soil 5 - Fine & 0.003 & 0.997 & 0.002 \\
\hline
\end{tabular}

on the amount of DI water used to prepare the aqueous extracts) and converted to a mixture of salts, each with a mass fraction $m_{i}$ by applying the ISORROPIA-II model (Fountoukis and Nenes, 2007) as described in Padró et al. (2010). The volume fraction of substance $i, \varepsilon_{i}$, is computed as follows:

$\varepsilon_{\mathrm{i}}=\frac{m_{i} / \rho_{i}}{\sum_{j}(m / \rho)_{j}}$

where $j$ refers to all substances present in the aerosol (soluble and insoluble). Table 3 contains information on the properties (molar mass, $M_{\mathrm{s}}$, density, $\rho_{\mathrm{s}}$, and hygroscopicity parameter, $\kappa)$ of salts that may be present in the mineral aerosol.
A closure analysis for $\kappa$ was performed by comparing the measured $\kappa_{\mathrm{CCN}}$ against predictions $\left(\kappa_{\mathrm{mix}}\right)$ using a volumeaverage mixing rule (Petters and Kreidenweis, 2007):

$\kappa_{\text {mix }}=\sum_{j} \varepsilon_{j} \kappa_{j}$

For all of the eight samples analyzed in this study, an excess of cations was found, with $\mathrm{Ca}^{2+}$ being the most dominant unbalanced cation. Since IC analysis did not measure $\mathrm{CO}_{3}^{2-}$, we postulate that all of the excess cations were balanced by $\mathrm{CO}_{3}^{2-}$, resulting in carbonate salts in the form of $\mathrm{CaCO}_{3}$. This is consistent with findings of Claquin et al. (1999) that show calcite to make up to $30 \%$ of the dust composition. Table 4 shows the inferred volume fractions of soluble salt and insoluble species from ISORROPIA-II along with the corresponding hygroscopicity parameter $(\kappa)$ determined using Eq. (5). It can be seen from Table 4 that the inferred $\kappa_{\text {mix }}$ for all samples is much smaller than that determined from the observed CCN activity of dry generated dust aerosol. This confirms that the presence of soluble fractions alone cannot explain hygroscopicity observed in the original dust samples, further supporting that the $\mathrm{CCN}$ activity observed by Kumar et al. (2011) for dry generated dust aerosol originated from water vapor adsorption onto the insoluble dust surface.

It was previously suggested by Koehler et al. (2009) that the presence of soluble contaminants in dust can be attributed to enhanced hygroscopicities in $\mathrm{CCN}$ activation measurements performed on wet generated dust aerosol. For the above statement to hold true for the dust samples analyzed in this study, dust and mineral aerosols would have to be composed of $\geq 25-80 \%$ by volume of soluble salts like 
$\left(\mathrm{NH}_{4}\right)_{2} \mathrm{SO}_{4}(\kappa=0.61)$ to display $\kappa$ of $\sim 0.2-0.5$ (Tables 1,2$)$. However, IC analysis performed on all eight samples did not reveal significant amounts of soluble salts in the bulk samples with a soluble volume fraction of less than $1 \%$ (Table 4). Sullivan et al. (2010) provided a possible explanation regarding the presence of particles produced in the first peak of calcite and ATD, and attributed those to a mixture of parent mineral particles plus secondary calcium bicarbonates, calcium hydrates as well as contributions from other undetected impurities that may have formed amorphous precipitates (given that we observe substantially smaller aerosol than in dry generation, it is likely that parent mineral particles are seldomly present). It may also be possible that slightly soluble compounds (such as $\mathrm{CaCO}_{3}$ ) can form metastable aerosol (e.g., Raymond and Pandis, 2002; Padró and Nenes, 2007) due to insufficient drying inside the diffusion dryers so that all of the material is available for solvation. This has been seen in our measurements, where assuming $\mathrm{CaCO}_{3}$ is fully soluble yields $\kappa \sim 0.97$ (vs. observed $\kappa_{\mathrm{CCN}} \sim 1.0$ and $x_{\text {exp }} \sim-1.5$ ). This suggests that the same behavior may also be occurring in regional dust samples when dissolved in water resulting in a high value of $\kappa$. It can be also argued that presence of dissolved soluble contaminants in the DI water can also result to the formation of the first hygroscopic peak. However, results from IC performed on DI water (blank sample) indicated negligible presence of dissolved ions impurities. For instance, the concentration of $\mathrm{Na}^{+}, \mathrm{K}^{+}$and $\mathrm{NH}_{4}^{+}$was below the detection limit, while the concentration of $\mathrm{Ca}^{2+}$ was lower by a factor of $10^{3}$ when compared to the IC results of dust samples. Similarly for anions, the only concentration detected by IC was for $\mathrm{SO}_{4}^{2-}$ and that was again lower by a factor of 300-2000. Therefore, residual ions in pure DI water are an unlikely contributor to the observed hygroscopicity of the first peak.

The analysis performed above questions the atmospheric relevance of $\mathrm{CCN}$ activity experiments using wet generated dust, and the usage of $\kappa$-KT for parameterizing its hygroscopicity. It also supports the approach of Kumar et al. (2009a, b, 2011) of using the exponents derived from the scale dependence of $s_{\mathrm{c}}$ on $D_{\text {dry }}$ to reveal the dominant activation physics. Since large-mode aerosol (whenever present during wet generation) closely matches the activation behavior of dry generated dust, we postulate that wetting of fresh dust does not irreversibly change its CCN activity. The activation kinetics however can be accelerated with dust cloud cycling.

\section{Implications for dust - warm cloud interactions}

Droplet activation in large-scale atmospheric models is often calculated from physically-based prognostic parameterizations (e.g., Abdul-Razzak and Ghan, 2000; Ming et al., 2006; Nenes and Seinfeld, 2003, Kumar et al., 2009b) that rely on solving the supersaturation balance equation (for a

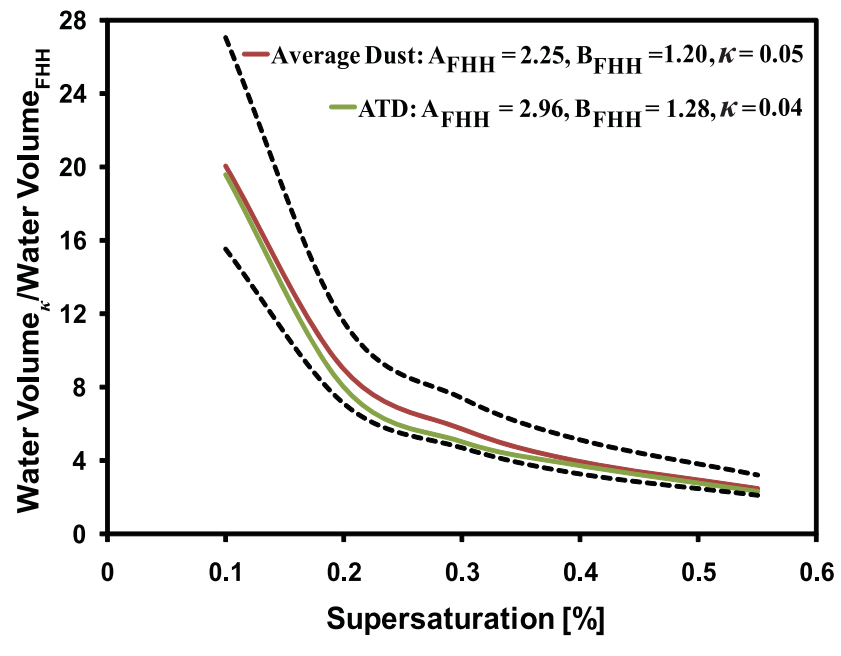

Fig. 7. Ratio of water volume required by KT over FHH-AT to activate $\mathrm{CCN}$ as a function of supersaturation. Simulations are performed with values of adsorption $\left(A_{\mathrm{FHH}}, B_{\mathrm{FHH}}\right)$ and $\kappa$ for average dust aerosol. Dashed lines represent simulation representing upper and lower limit of dust relevant adsorption parameters.

1-D parcel) to determine parcel maximum supersaturation, $s_{\max }$. The $s_{\max }$ corresponds to the point where droplet activation terminates in the cloud, and occurs when supersaturation generated from expansion cooling balances supersaturation depletion from condensation of water vapor on pre-existing aerosol particles. The level of $s_{\max }$ in clouds depends on the competition between $\mathrm{CCN}$ for available water vapor that is required to activate $\mathrm{CCN}$ to cloud droplets.

Kumar et al. (2009a) found that the volume of water required by particles to activate to cloud droplets at a given supersaturation can vary significantly between KT and FHHAT. This behavior is also shown in Fig. 7 which compares the ratio of water volume at the critical wet diameter, $D_{\mathrm{c}}$, required by KT over FHH-AT for supersaturations between $0.05 \%$ and $0.6 \%$. The $A_{\mathrm{FHH}}, B_{\mathrm{FHH}}$, and $\kappa$ used in Fig. 7 are representative of dust samples analyzed in this study and by Kumar et al. (2011). It can be seen from Fig. 7 that for a particle to activate by KT, up to 15 times more water volume is required for activation compared to particles activating via FHH-AT at the same critical supersaturation. A high value of water volume at $D_{\mathrm{c}}$ implies that large amount of water vapor would be required by the $\mathrm{CCN}$ to form a cloud droplet. Integration over the entire $\mathrm{CCN}$ population would increase competition for water vapor, lead to a decrease in $s_{\max }$, and cause a decrease in cloud droplet number, $N_{\mathrm{d}}$.

Based on the above, it becomes clear that the choice of activation theory can have a strong impact on $s_{\max }$ and $N_{\mathrm{d}}$. For an externally mixed population of KT and FHH-AT particles, the treatment of Kumar et al. (2009b) is sufficient. However, during atmospheric transport, fresh dust undergoes aging and acquires soluble species like $\left(\mathrm{NH}_{4}\right)_{2} \mathrm{SO}_{4}$ on its surface (Levin et al., 1996). Similarly, dust generated from 
dry lakebeds (or playas) are known to contain significant amounts of soluble salts (Pratt et al., 2010). The presence of such soluble salts on dust surface can affect water-particle interactions with implication to the dust CCN activity. Below, we address the effect of soluble salts on dust surface to droplet equilibrium behavior.

We adopt a shell-and-core model with the core representing insoluble dust and shell consisting of a layer of soluble salt. Based on laboratory dust CCN activation measurements, Kumar et al. (2011) found typical fresh dust sizes to range between 100 and $500 \mathrm{~nm}$. As ageing occurs, it is expected that dry particle size will increase; therefore in our approach we consider a core-shell model where the insoluble core does not go below $50 \mathrm{~nm}$ (a lower limit of fresh dust). The water vapor saturation ratio, $S$, of an aerosol particle in equilibrium with surrounding water vapor can be expressed as (Seinfeld and Pandis, 2006):

$S=a_{\mathrm{w}} \gamma_{\mathrm{w}} \exp \left(\frac{4 \sigma_{\mathrm{w}} M_{\mathrm{w}}}{R T \rho_{\mathrm{w}} D_{\mathrm{p}}}\right)$

where $a_{\mathrm{W}}$ is the water activity of the particle, $\gamma_{\mathrm{w}}$ is the activity coefficient for water, and other parameters as defined above. The exponential in Eq. (6) is commonly referred to as the curvature or Kelvin effect. For a completely insoluble aerosol particle like fresh dust, $a_{\mathrm{w}}$, is controlled by the adsorption of the water vapor on the insoluble surface such that Eq. (6) reduces to Eq. (1) (when adsorption is modeled using the FHH adsorption isotherm).

Given that the water adsorbed on the surface must be in equilibrium with the surrounding aqueous phase and the water vapor in the gas, the $a_{\mathrm{w}}$ that accounts for both the Raoult and adsorption effects is given as:

$a_{\mathrm{w}}=x_{\mathrm{w}} f(\Theta)$

where $x_{\mathrm{w}}$ is the mole fraction of water in the droplet and represents water activity depression due to solute effects. $f(\Theta)$ represents water vapor adsorption effect on $a_{\mathrm{w}}$, where $\Theta$ is the number of water monolayers adsorbed on the dry particle core. $x_{\mathrm{W}}$ is related to the mole fraction of the soluble salt, $x_{\mathrm{s}}$, as $x_{\mathrm{W}}=1-x_{\mathrm{s}}$. Invoking the dilute approximation gives $x_{\mathrm{s}}=\frac{n_{\mathrm{s}}}{n_{\mathrm{T}}} \approx \frac{n_{\mathrm{s}}}{n_{\mathrm{w}}}$, where $n_{\mathrm{s}}$ is the moles of solute, $n_{\mathrm{T}}$ is the total moles in the aqueous phase, and $n_{\mathrm{w}}$ is the moles of water in the droplet. Therefore,

$x_{\mathrm{s}}=\frac{n_{\mathrm{s}}}{n_{\mathrm{W}}}=\frac{\left(\frac{V_{\mathrm{s}} \rho_{\mathrm{s}} v}{M_{\mathrm{s}}}\right)}{\left(\frac{V_{\mathrm{w}} \rho_{\mathrm{w}}}{M_{\mathrm{W}}}\right)}$

where $\rho_{\mathrm{s}}, M_{\mathrm{s}}$, and $v$ are density, molecular mass and effective van't Hoff factor of the solute, respectively. $V_{\mathrm{s}}$ and $V_{\mathrm{w}}$ are the volume of the salt and water in the aqueous phase, respectively.

For a given insoluble volume fraction, $\varepsilon_{i}$ and diameter of the dust core, $D_{\text {core }}$, the size of the dry particle, $D_{\text {dry }}$, can be estimated as:

$D_{\text {dry }}=D_{\text {core }} / \varepsilon_{\mathrm{i}}^{1 / 3}$
The volume of the soluble fraction, $\varepsilon_{\mathrm{s}}$, is given by $\varepsilon_{\mathrm{s}}=1-$ $\varepsilon_{\mathrm{i}}$. Therefore, the volume of the soluble fraction, $V_{\mathrm{s}}$, can be defined as:

$V_{\mathrm{s}}=\varepsilon_{\mathrm{s}}\left(\frac{\pi}{6}\right) D_{\mathrm{dry}}^{3}$

Substituting $V_{\mathrm{S}}$ from Eq. (10) into Eq. (8) and expressing $V_{\mathrm{w}}=V_{\mathrm{T}}-V_{\mathrm{i}}$ where $V_{\mathrm{w}}$ is the volume of water in droplet, $V_{\mathrm{T}}$ is the droplet volume and $V_{\mathrm{i}}$ is the volume of the insoluble core gives:

$x_{\mathrm{s}}=\frac{\left(\frac{\varepsilon_{\mathrm{s}}(\pi / 6) D_{\mathrm{dry}}^{3} \rho_{\mathrm{s}} v}{M_{\mathrm{s}}}\right)}{\left(\frac{\left(V_{\mathrm{T}}-V_{\mathrm{i}}\right) \rho_{\mathrm{w}}}{M_{\mathrm{w}}}\right)}=\frac{\varepsilon_{\mathrm{s}} D_{\mathrm{dry}}^{3} \rho_{\mathrm{s}} v M_{\mathrm{w}}}{M_{\mathrm{s}}\left(D_{\mathrm{p}}^{3}-\varepsilon_{\mathrm{i}} D_{\mathrm{dry}}^{3}\right) \rho_{\mathrm{w}}}$

Substituting the hygroscopicity parameter, $\kappa$, as $\kappa=\frac{\rho_{\mathrm{s}} v M_{\mathrm{W}}}{M_{\mathrm{s}} \rho_{\mathrm{w}}}$ into Eq. (11) gives $x_{\mathrm{s}}=\frac{\varepsilon_{\mathrm{s}} D_{\mathrm{dry}}^{3} \kappa}{\left(D_{\mathrm{p}}^{3}-\varepsilon_{\mathrm{i}} D_{\mathrm{dry}}^{3}\right)}$. Now expressing $x_{\mathrm{w}}$ in terms of $x_{\mathrm{s}}$ gives $x_{\mathrm{w}}=1-x_{\mathrm{s}}=1-\frac{\varepsilon_{\mathrm{s}} D_{\mathrm{dry}}^{3} \kappa}{\left(D_{\mathrm{p}}^{3}-\varepsilon_{\mathrm{i}} D_{\mathrm{dry}}^{3}\right)}$.

Kumar et al. (2009b) defined surface coverage, $\Theta$, as the number of monolayers of water adsorbed on the particle. As water vapor is adsorbed only on the dry insoluble core, $\Theta$ is given as:

$\Theta=\left(\frac{D_{\mathrm{p}}-\varepsilon_{\mathrm{i}}^{1 / 3} D_{\text {dry }}}{2 D_{\mathrm{H}_{2} \mathrm{O}}}\right)$

where $\varepsilon_{\mathrm{i}}^{1 / 3} D_{\text {dry }}$ is the diameter of the insoluble core, and, $D_{\mathrm{H}_{2} \mathrm{O}}$ is the diameter of the adsorbed water molecule. According to Kumar et al. (2009b), $f(\Theta)=$ $\exp \left(-A_{\mathrm{FHH}} \Theta^{-B_{\mathrm{FHH}}}\right)$. Substituting into Eq. (12) gives:

$f(\Theta)=\exp \left[-A_{\mathrm{FHH}}\left(\frac{D_{\mathrm{p}}-\varepsilon_{\mathrm{i}}^{1 / 3} D_{\text {dry }}}{2 D_{\mathrm{H}_{2} \mathrm{O}}}\right)^{-B_{\mathrm{FHH}}}\right]$

Thus combined $a_{\mathrm{w}}$ can be obtained using Eqs. (7), (11) and (13) as:

$a_{\mathrm{w}}=\left[1-\frac{\varepsilon_{\mathrm{s}} D_{\mathrm{dry}}^{3} \kappa}{\left(D_{\mathrm{p}}^{3}-\varepsilon_{\mathrm{i}} D_{\mathrm{dry}}^{3}\right)}\right] \exp \left[-A_{\mathrm{FHH}}\left(\frac{D_{\mathrm{p}}-\varepsilon_{\mathrm{i}}^{1 / 3} D_{\mathrm{dry}}}{2 D_{\mathrm{H}_{2} \mathrm{O}}}\right)^{-B_{\mathrm{FHH}}}\right]$

Substituting $a_{\mathrm{w}}$ from Eq. (14) into Eq. (6), assuming ideality $\left(\gamma_{\mathrm{w}}=1\right)$ and expanding the exponential and taking the first order terms gives:

$s=\frac{4 \sigma M_{\mathrm{w}}}{\rho_{\mathrm{w}} \mathrm{RTD}_{\mathrm{p}}}-\frac{\varepsilon_{\mathrm{s}} D_{\mathrm{dry}}^{3} \kappa}{\left(D_{\mathrm{p}}^{3}-\varepsilon_{\mathrm{i}} D_{\mathrm{dry}}^{3}\right)}-A_{\mathrm{FHH}}\left(\frac{D_{\mathrm{p}}-\varepsilon_{\mathrm{i}}^{1 / 3} D_{\mathrm{dry}}}{2 D_{\mathrm{H}_{2} \mathrm{O}}}\right)^{-B_{\mathrm{FHH}}}$

where $s$ is the equilibrium supersaturation defined as $s=S-1$.

Equation (15) represents water vapor supersaturation over an aerosol particle (consisting of insoluble core with a soluble coating) in equilibrium with the surrounding water vapor. 


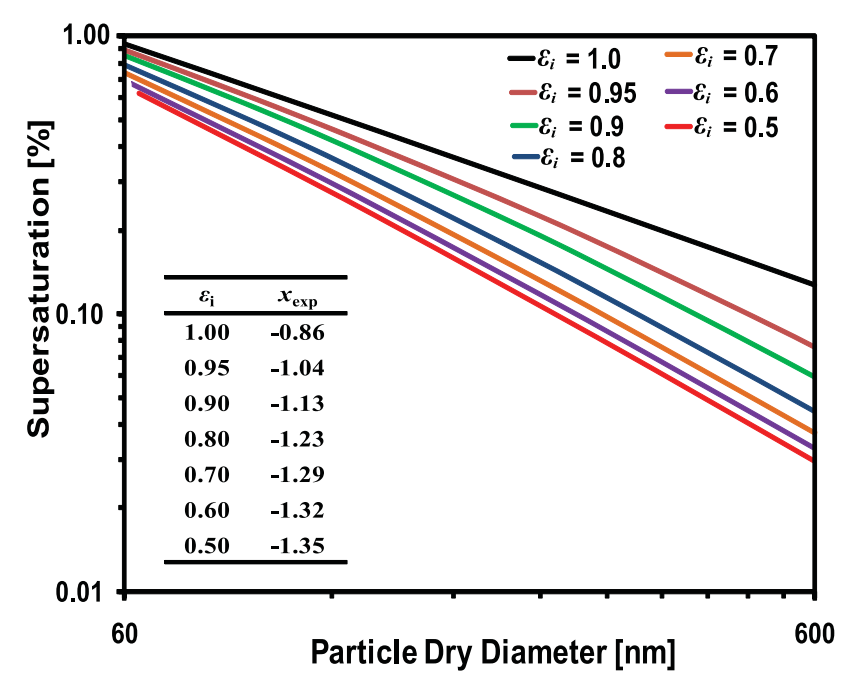

Fig. 8. $s_{\mathrm{C}}-D_{\mathrm{dry}}$ lines for different values of $\varepsilon_{\mathrm{i}}$ computed at $\sigma_{\mathrm{W}}=0.072 \mathrm{~N} \mathrm{~m}^{-1}, T=298.15 \mathrm{~K}, A_{\mathrm{FHH}}=2.25, B_{\mathrm{FHH}}=1.20$, $\kappa=0.10$. The inset table shows theoretical exponent associated with $s_{\mathrm{c}}-D_{\mathrm{dry}}$ lines shown in the main figure.

As Eq. (15) is specific to an aerosol particle with a finite insoluble core but variable soluble coating, it reduces to Eq. (1) for a completely insoluble particle as $\varepsilon_{\mathrm{i}} \rightarrow 1$. In this study, Eq. (15) will be referred to as the Unified Dust Activation Framework.

Figure 8 shows the relationship between dry diameter, $D_{\text {dry }}$, and critical supersaturation, $s_{\mathrm{c}}$, for different insoluble volume fractions, $\varepsilon_{\mathrm{i}}$, computed for $\kappa=0.10$, average adsorption parameters of fresh dust $\left(A_{\mathrm{FHH}}=2.25, B_{\mathrm{FHH}}=1.20\right)$, surface tension of water, $\sigma_{\mathrm{w}}=0.072 \mathrm{~N} \mathrm{~m}^{-1}$, and temperature, $T=298.15 \mathrm{~K}$. It can be seen from Fig. 8 that as the insoluble volume fraction, $\varepsilon_{i}$, of the dry aerosol decreases from 1.0 to 0.5 , the threshold of cloud droplet nucleation on pre-existing aerosol particles increases significantly. Furthermore, as $\varepsilon_{\mathrm{i}}$ starts decreasing from 1.0, the exponent derived from the $s_{\mathrm{c}}-D_{\text {dry }}$ relationships changes from -0.85 (representative of FHH-AT) and starts approaching that of the completely soluble particle with exponent equal to -1.50 (shown by inset Table in Fig. 8). This implies that the activation mechanism changes from a $\mathrm{FHH}$ AT regime $(-1.25<$ exponent $<-0.85)$ to the regime where both KT and FHH-AT may be applicable with exponent between -1.25 and -1.50 .

Figure 9 shows the effect of $\varepsilon_{i}$ on the magnitude of derived exponent for three different values of $\kappa$ equal to $0.1,0.61$, and 1.0 computed at $A_{\mathrm{FHH}}=2.25$ and $B_{\mathrm{FHH}}=1.20$. It can be seen that as $\varepsilon_{\mathrm{i}}$ starts decreasing from 1.0, the magnitude of the exponent also starts changing from -0.85 (representative of FHH-AT) and starts approaching that of KT with exponent equal to -1.5 . The effect of different solute type (representative of different $\kappa$ ) to $a_{\mathrm{w}}$, and its corresponding, $\varepsilon_{\mathrm{S}}\left(=1-\varepsilon_{\mathrm{i}}\right)$, to the derived exponent is also presented in Fig. 9. It can be

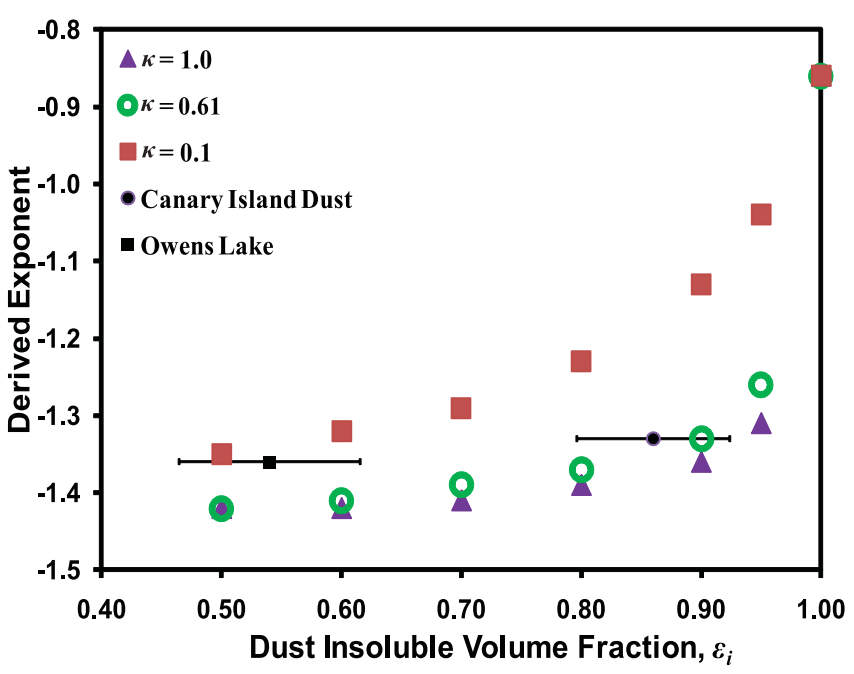

Fig. 9. Derived theoretical exponent as a function of $\varepsilon_{\mathrm{i}}$ for different values of $\kappa$ computed at $A_{\mathrm{FHH}}=2.25$ and $B_{\mathrm{FHH}}=1.20$. Also shown are data points for Canary Island Dust and Owens Lake dust (data obtained from Kumar et al., 2009a).

seen that as $\kappa$ increases from 0.1 (representative of dust containing oxidized organics) to 0.61 (representative of dust containing $\left.\left(\mathrm{NH}_{4}\right)_{2} \mathrm{SO}_{4}\right)$, even a small decrease in $\varepsilon_{\mathrm{i}}$ can cause an appreciable change in the exponent magnitude, with implications to particle water interactions. Similar behavior is seen when going from $\kappa=0.61$ to $\kappa=1.0$. The results shown in Figs. 8 and 9 further substantiate the findings by Kumar et al. $(2009 \mathrm{a}, 2011)$ that $\mathrm{CCN}$ activity of fresh dust $\left(\varepsilon_{\mathrm{s}} \sim 0.0\right)$ can be parameterized by FHH-AT and suggested a combined framework may be required to describe $\mathrm{CCN}$ activity of dust with a significant soluble fraction.

The proposed unified framework (Eq. 15) is evaluated against experimental measurements of $\mathrm{CCN}$ activity of $\mathrm{Ca}-$ nary Island Dust (CID) and Owens Lake (OL) dust samples that are known to contain high concentration of soluble salts as high as $37 \%$ by mass in Owens Lake (Reheis, 1997) and about $14 \%$ sulphates and $5 \%$ Calcium-rich salts by volume in dust samples collected around Canary Island (Kandler et al., 2009). Kumar et al. (2009a) found $x_{\exp }$ equal to -1.33 and -1.36 for CID and OL that could not be reconciled by KT or FHH-AT alone. A revised analysis of the exponents for CID and OL dust based on approximate salt volume fractions determined from the literature demonstrates that the unified approach (Eq. 15) can be used to reconcile such exponents (also shown in Fig. 9). A thorough assessment of the framework would require size resolved composition and $\mathrm{CCN}$ activation measurement of dust samples with significant amounts of solute and is left to be addressed by future studies. 


\section{Conclusions}

In this study, the $\mathrm{CCN}$ properties and droplet activation kinetics of aerosol wet generated from regional dust samples and individual minerals (clays, calcite, and quartz) were measured. The aerosols were generated wet in the lab, and properties were measured using the Scanning Mobility CCN Analysis (Moore et al., 2010). Measurement of dust size distributions indicated unimodal distributions for regional dust samples with particle sizes observed as low as $40 \mathrm{~nm}$. These measurements demonstrate that particles generated via wet atomization are up to ten times smaller those generated by the dry soft-saltation technique. For most minerals (ATD, calcite, illite, and kaolinite) a bimodal dry size distribution was obtained. Comparisons with the number size distribution generated by the dry technique suggests that the second observed peak in the wet generation method could be a consequence of the external mixture containing more hygroscopic particles and the less hydrophilic particle mode. Montmorillonite clays were found to behave differently when mixed with water as a unimodal size distribution was obtained with the wet generation technique. This difference in patterns of number size distribution between montmorillonite (unimodal) and illite, kaolinite (bimodal) is related to the aluminosilicate layer-layer interactions.

Measurements of dust CCN activity indicated that the wet generated particles were significantly more $\mathrm{CCN}$ active (with $\kappa$ ranging between $0.15-0.61$ ) than those generated from the dry soft-saltation technique (with $\kappa<0.05$ ). For almost all wet generated regional dust aerosols, $x_{\exp }$ is $\sim-1.5$ (with the exception of ATD), while a much lower $x_{\exp } \sim-(0.9 \pm 0.2)$ was observed for dry generated dust aerosol. Ion Chromatography (IC) analysis performed on regional dust samples indicates negligible soluble fractions. The expected hygroscopicity from this composition was much lower than observed for both wet and dry generated aerosol. All together, these results confirm that the presence of soluble fractions alone cannot explain fresh dust CCN activity, and the effects of water vapor adsorption must be included to comprehensively describe the CCN activity of dry dust. These results also question the atmospheric relevance of past studies that used mineral dust aerosol generated with the wet atomization method.

Based on threshold droplet growth analysis, we found that wet generated dust aerosol does not exhibit delayed activation kinetics. This behavior of similar activation kinetics for wet generated dust (compared to $\left(\mathrm{NH}_{4}\right)_{2} \mathrm{SO}_{4}$ ) is different from that observed for dry generated mineral aerosol that exhibits retarded activation kinetics and a reduced effective water vapor uptake coefficient (by 30-80\%) that is consistent with longer timescale associated with adsorption than absorption.

To account for the CCN activity of dust containing soluble salt fraction, we propose a new framework of CCN activation that accounts for concurrent effects of solute and water vapor adsorption. This unified framework is based on the core-and-shell model and describes equilibrium supersaturation as a function of adsorption parameters, hygroscopicity parameter of the soluble fraction, size of the dry particle, and insoluble and soluble volume fractions. As expected, the framework predicts that as $\varepsilon_{i}$ decreases, $x_{\exp }$ changes from -0.85 (FHH-AT limit) and to -1.50 (KT limit). The new framework predicts values of $x_{\exp }$ consistent with published $\mathrm{CCN}$ activity of playa salts that tend to contain a substantial soluble fraction.

An important finding of this study is that the process of wet generation tends to generate hygroscopic particles that are not representative of the parent dust. Therefore, published work showing an augmented $\mathrm{CCN}$ activity from wetting may be affected by an artifact induced by the wet generation method. The method, however, can still generate a less hydrophilic peak, with a size and degree of hydrophilicity similar to dry generated dust; this implies that the process of wetting and drying of dust particles may not irreversibly change its hydrophilicity. The wet generation method however can still be used to explore the dependence of $x_{\exp }$ on $A_{\mathrm{FHH}}$, $B_{\mathrm{FHH}}$ and soluble volume fraction if the size-dependent composition of the particles generated can be measured, and will be the subject of future study.

\section{Nomenclature}

\begin{tabular}{ll}
\hline Symbol & Description \\
\hline$s_{\mathrm{c}}$ & Critical supersaturation \\
$s$ & Supersaturation \\
$S$ & Water vapor saturation ratio \\
$a_{\mathrm{w}}$ & Water activity of particle \\
$x$ & Power law exponent relating $s_{\mathrm{c}}$ and $D_{\mathrm{dry}}$ \\
$D_{\mathrm{dry}}$ & Dry CCN diameter \\
$C$ & Power law constant \\
$x_{\mathrm{exp}}$ & Experimental exponent \\
$x_{\mathrm{FHH}}$ & FHH-AT exponent \\
$A_{\mathrm{FHH}}$ & FHH adsorption isotherm parameter \\
$B_{\mathrm{FHH}}$ & FHH adsorption isotherm parameter \\
$\Theta$ & Number of monolayers of water \\
& adsorbed on the particle \\
$\gamma_{\mathrm{w}}$ & Activity coefficient of water \\
$x_{\mathrm{w}}$ & Mole fraction of water \\
$x_{\mathrm{S}}$ & Mole fraction of the soluble salt \\
$n_{\mathrm{w}}$ & Moles of water in the droplet \\
$n_{\mathrm{s}}$ & Moles of soluble salt in the droplet \\
$n_{\mathrm{T}}$ & Total moles in the droplet aqueous phase \\
$V_{\mathrm{S}}$ & Volume of the salt in the aqueous phase \\
$V_{\mathrm{w}}$ & Volume of the water in the aqueous phase \\
$\rho_{\mathrm{s}}$ & Density of solute \\
$\rho_{\mathrm{w}}$ & Density of water \\
$M_{\mathrm{s}}$ & Molecular Mass of solute \\
$M_{\mathrm{w}}$ & Molecular Mass of water \\
$v$ & Effective van't Hoff factor of the solute \\
$f(\Theta)$ & Water vapor adsorption effect on $a_{\mathrm{w}}$ \\
$D_{\mathrm{c}}$ & \\
&
\end{tabular}




\begin{tabular}{ll}
$\Delta D_{\mathrm{p}}$ & Droplet size difference at OPC \\
$D_{\mathrm{p}}$ & Droplet diameter \\
$R$ & Universal gas constant \\
$T$ & Average column temperature \\
$\alpha_{\mathrm{c}}$ & Water vapor uptake coefficient \\
$\sigma_{\mathrm{w}}$ & Surface tension \\
$\kappa$ & Hygroscopicity parameter \\
$\kappa_{\mathrm{mix}}$ & Predicted hygroscopicity parameter \\
$\kappa_{\mathrm{CCN}}$ & Experimental hygroscopicity parameter \\
$\varepsilon$ & Volume fraction \\
$\varepsilon_{\mathrm{i}}$ & Volume fraction of the insoluble core \\
$\varepsilon_{\mathrm{S}}$ & Volume fraction of the soluble part \\
$V_{\mathrm{S}}$ & Volume of soluble fraction in the droplet \\
$V_{\mathrm{T}}$ & Volume of the droplet \\
$V_{\mathrm{w}}$ & Volume of water in the droplet \\
$V_{\mathrm{i}}$ & Volume of insoluble core in the droplet \\
$m$ & Mass fraction \\
$D_{\mathrm{H}_{2} \mathrm{O}}$ & Diameter of water molecule \\
$D_{\mathrm{core}}$ & Diameter of dust core \\
\hline
\end{tabular}

Acknowledgements. This work was supported with grants from NOAA ACC and NSF CAREER. Publication was also supported by the Greek National Centre of Scientific Research "Demokritos". We thank Marcus Trail for help with Ion Chromatography measurements, Shannon Capps for help with using ISORROPIA-II, and Ricardo Morales for valuable discussions on the combined/unified approach. We also thank Mike Bergin for providing the MOUDI Impactor.

Edited by: M. Ammann

\section{References}

Abdul-Razzak, H. and Ghan, S. J.: A parameterization of aerosol activation: 2. Multiple aerosol types, J. Geophys. Res., 105(D6), 6837-6844, 2000.

Bougiatioti, A., Fountoukis, C., Kalivitis, N., Pandis, S. N., Nenes, A., and Mihalopoulos, N.: Cloud condensation nuclei measurements in the marine boundary layer of the Eastern Mediterranean: CCN closure and droplet growth kinetics, Atmos. Chem. Phys., 9, 7053-7066, doi:10.5194/acp-9-7053-2009, 2009.

Claquin, T., Schulz, M., and Balkanski, Y. J.: Modeling the mineralogy of atmospheric dust sources. J. Geophys. Res., 104(D18), 22243-22256, 1999.

DeMott, P. J., Sassen, K., Poellot, M. R., Baumgardner, D., Rogers, D. C., Brooks, S. D., Prenni, A. J., and Kreidenweis, S. M.: African dust aerosols as atmospheric ice nuclei, Geophys. Res. Lett., 30(14), 1732, doi:10.1029/2003GL017410, 2003.

Farmer, V. C.: Mineralogical Society Monograph 4: The Infrared Spectra of Minerals, 539 pp., 1974.

Field, P. R., Möhler, O., Connolly, P., Krämer, M., Cotton, R., Heymsfield, A. J., Saathoff, H., and Schnaiter, M.: Some ice nucleation characteristics of Asian and Saharan desert dust, Atmos. Chem. Phys., 6, 2991-3006, doi:10.5194/acp-6-2991-2006, 2006.

Fountoukis, C. and Nenes, A.: ISORROPIA II: a computationally efficient thermodynamic equilibrium model for $\mathrm{K}^{+}, \mathrm{Ca}^{2+}$, $\mathrm{Mg}^{2+}, \mathrm{NH}_{4}^{+}, \mathrm{Na}^{+}, \mathrm{SO}_{4}^{2-}, \mathrm{NO}_{3}^{-}, \mathrm{Cl}^{-}, \mathrm{H}_{2} \mathrm{O}$ aerosols, At- mos. Chem. Phys., 7, 4639-4659, doi:10.5194/acp-7-4639-2007, 2007.

Gibson, E. R., Hudson, P. K., and Grassian, V. H.: Aerosol chemistry and climate: Laboratory studies of carbonate component of mineral dust and its reaction products, Geophys. Res. Lett., 33, L13811, doi:10.1029/2006GL026386, 2006.

Gustafsson, R. J., Orlov, A., Badger, C. L., Griffiths, P. T., Cox, R. A., and Lambert, R. M.: A comprehensive evaluation of water uptake on atmospherically relevant mineral surfaces: DRIFT spectroscopy, thermogravimetric analysis and aerosol growth measurements, Atmos. Chem. Phys., 5, 34153421, doi:10.5194/acp-5-3415-2005, 2005.

Hatch, C. D., Gierlus, K. M., Schuttlefield, J. D., and Grassian, V. H.: Water adsorption and cloud condensation nuclei activity of calcite and calcite coated with model humic and fulvic acids, Atmos. Environ., 42, 5672-5684, 2008.

Herich, H., Tritscher, T., Wiacek, A., Gysel, M., Weingartner, E., Lohmann, U., Baltensperger, U., and Cziczo, D. J.: Water uptake of clay and desert dust aerosol particles at sub- and supersaturated water vapor conditions, Phys. Chem. Chem. Phys., 11, 7804-7809, doi:10.1039/b901585j, 2009.

Hudson, P., Gibson, E. R., Young, M. A., Kleiber, P. D., and Grassian, V. H.: Coupled infrared extinction and size distribution measurements for several clay components of mineral dust aerosol, J. Geophys. Res., 113, D01201, doi:10.1029/2007JD008791, 2008.

Kandler, K., Schütz, L., Deutscher, C., Ebert, M., Hofmann, H., Jäckel, S., Jaenicke, R., Knippertz, P., Lieke, M., Massling, A., Petzold, A., Schladitz, A., Weinzierl, B., Wiedensohler, A., Zorn, S., and Weinbruch, S.: Size distribution, mass concentration, chemical and mineralogical composition and derived optical parameters of the boundary layer aerosol at Tinfou, Morocco, during SAMUM 2006, Tellus B, 61, 32-50, doi:10.1111/j.16000889.2008.00385.x, 2009.

Kelly, J. T., Chuang, C. C., and Wexler, A. S.: Influence of dust composition on cloud droplet formation, Atmos. Environ., 41, 2904-2916, 2007.

Koehler, K. A., Kreidenweis, S. M., DeMott, P. J., Petters, M. D., Prenni, A. J., and Carrico, C. M.: Hygroscopicity and cloud droplet activation of mineral dust aerosol, Geophys. Res. Lett., 36, L08805, doi:10.1029/2009GL037348, 2009.

Köhler, H., The nucleus in and the growth of hygroscopic droplets, Trans. Faraday Soc., 32(2), 1152-1161, 1936.

Kumar, P., Sokolik, I. N., and Nenes, A.: Parameterization of cloud droplet formation for global and regional models: including adsorption activation from insoluble CCN, Atmos. Chem. Phys., 9, 2517-2532, doi:10.5194/acp-9-2517-2009, 2009a.

Kumar, P., Nenes, A., and Sokolik, I. N.: Importance of adsorption for $\mathrm{CCN}$ activity and hygroscopic properties of mineral dust aerosol, Geophys. Res. Lett., 36, L24804, doi:10.1029/2009GL040827, 2009b.

Kumar, P., Sokolik, I. N., and Nenes, A.: Measurements of cloud condensation nuclei activity and droplet activation kinetics of fresh unprocessed regional dust samples and minerals, Atmos. Chem. Phys., 11, 3527-3541, doi:10.5194/acp-11-3527-2011, 2011.

Lafon, S., Sokolik, I. N., Rajot, J. L., Caquineau, S., and Gaudichet, A.: Characterization of iron oxides in mineral dust aerosols: Implications to light absorption. J. Geophys. Res., 111, D21207, 
doi:10.1029/2005JD007016, 2006.

Lance, S., Medina, J., Smith, J. N., and Nenes, A.: Mapping the operation of the DMT continuous flow CCN counter, Aerosol Sci. Tech., 40, 242-254, 2006.

Levin, Z. and Cotton, W. R.: Aerosol Pollution Impact on Precipitation: A scientific review, Springer Press., 2008.

Levin, Z., Ganor, E., and Gladstein, V.: The effects of dust particles coated with sulfate on rain formation in the Eastern Mediterranean, J. Appl. Meteorol., 35, 1511-1523, 1996.

Moore, R., Nenes, A., and Medina, J.: Scanning Mobility CCN Analysis - A method for fast measurements of size resolved CCN distributions and activation kinetics, Aerosol Sci. Tech., 44, 861871, 2010.

Ming, Y., Ramaswamy, V., Donner, L. J., and Phillips, V. T. J.: A new parameterization of cloud droplet activation applicable to general circulation models, J. Atmos. Sci., 63, 1348-1356, 2006.

Nenes, A. and Seinfeld, J. H.: Parameterization of cloud droplet formation in global climate models, J. Geophys. Res., 108(D14), 4415, doi:10.1029/2002JD002911, 2003.

Padró, L. T. and Nenes, A.: Cloud droplet activation: solubility revisited, Atmos. Chem. Phys. Discuss., 7, 2325-2355, doi:10.5194/acpd-7-2325-2007, 2007.

Padró, L. T., Tkacik, D., Lathem, T., Hennigan, C., Sullivan, A. P., Weber, R. J., Huey, L. G., and Nenes, A.: Investigation of CCN relevant properties and droplet growth kinetics of water-soluble aerosol fraction in Mexico City, J. Geophys. Res, 115, D09204, doi:10.1029/2009JD013195, 2010.

Petters, M. D. and Kreidenweis, S. M.: A single parameter representation of hygroscopic growth and cloud condensation nucleus activity, Atmos. Chem. Phys., 7, 1961-1971, doi:10.5194/acp-71961-2007, 2007.

Pratt, K. A, Twohy, C. H., Murphy, S. M., Moffet, R. C., Heymsfield, A. J., Gaston, C. J., DeMott, P. J., Field, P. R., Henn, T. R., Rogers, D. C., Gilles, M. K., Seinfeld, J. H., and Prather, K. A.: Observation of playa salts as nuclei in orographicwave clouds, J. Geophys. Res., 115, D15301, doi:10.1029/2009JD013606, 2010.

Pruppacher, H. R. and Klett, J. D.: Microphysics of clouds and precipitation 2nd ed., Kluwer Academic Publishers, Boston, MA, 1997.

Radhi, M., Box, M. A., Box, G. P., Mitchell, R. M., Cohen, D. D., Stelcer, E., and Keywood, M. D.: Optical, physical and chemical characteristics of Australian continental aerosols: results from a field experiment, Atmos. Chem. Phys., 10, 5925-5942, doi:10.5194/acp-10-5925-2010, 2010.
Raymond, T. M. and Pandis, S. N.: Cloud activation of singlecomponent organic aerosol particles, J. Geophys. Res, 107(D24), 4787, doi:10.1029/2009JD002159, 2002.

Reheis, M. C.: Dust deposition downwind of Owens (Dry) Lake, 1991-1994,Preliminary findings, 102(D22), 2599926008, 1997.

Roberts, G. and Nenes, A.: A continuous-flow streamwise thermal gradient CCN chamber for atmospheric measurements, Aerosol Sci. Tech., 39, 206-221, 2005.

Rosenfeld, D., Rudich, Y., and Lahav, R.: Desert dust suppressing precipitation: A possible desertification feedback loop, P. Natl. Acad. Sci. USA, 98(11), 5975-5980, 2001.

Schuttlefield, J. D., Cox, D., and Grassian, V. H.: An investigation of water uptake on clays minerals using ATR-FTIR spectroscopy coupled with quartz crystal microbalance measurements, J. Geophys. Res., 112, D21303, doi:10.1029/2007JD008973, 2007.

Seinfeld, J. H. and Pandis, S. N.: Atmospheric Chemistry and Physics, John Wiley, New York, USA, 767-773, 2006.

Song, C. H., Maxwell-Meier, K., Weber, R. J., Kapustin, V., and Clarke, A.: Dust composition and mixing state inferred from airborne composition measurements during ACE-Asia C130 Flight \#6, Atmos. Environ., 39, 359-369, 2005.

Sorjamaa, R. and Laaksonen, A.: The effect of $\mathrm{H}_{2} \mathrm{O}$ adsorption on cloud drop activation of insoluble particles: a theoretical framework, Atmos. Chem. Phys., 7, 6175-6180, doi:10.5194/acp-76175-2007, 2007.

Sullivan, R. C., Moore, M. J. K., Petters, M. D., Kreidenweis, S. M., Roberts, G. C., and Prather, K. A.: Effect of chemical mixing state on the hygroscopicity and cloud nucleation properties of calcium mineral dust particles, Atmos. Chem. Phys., 9, 33033316, doi:10.5194/acp-9-3303-2009, 2009.

Sullivan, R. C., Moore, M. J. K., Petters, M. D., Kreidenweis, S. M., Qafoku, O., Laskin, A., Roberts, G. C., and Prather, K. A.: Impact of particle generation method on the apparent hygroscopicity of insoluble mineral particles, Aerosol Sci. Tech., 44, 10, 830-846, 2010.

Usher, C. R., Michel, A. E., and Grassian, V. H.: Reactions on mineral dust, Chem. Rev., 103, 4883-4939, 2003.

Vlasenko, A., Sjögren, S., Weingartner, E., Gäggeler, H. W., and Ammann, M.: Generation of Submicron Arizona Test Dust Aerosol: Chemical and Hygroscopic Properties, Aerosol Sci. Tech., 39 (5), 452-460, 2005. 